\title{
Elaboração de Manual de Orientações sobre Hipertermia Maligna para Pacientes
}

\author{
Elaboration of a Guidance Manual on Malignant \\ Hyperthermia for Patients
}

\author{
Elaboración del Manual de Directrices \\ sobre Hipertermia Maligna
}

\author{
Gislene Rodrigues ${ }^{1}$, Helga Cristina Almeida da Silva²
}

\begin{abstract}
1.Enfermeira, Mestre em Ciências. Universidade Federal de São Paulo (UNIFESP). São Paulo-SP, Brasil. 2.MD, PhD, Coordenadora do CEDHIMA (Centro de Estudo, Diagnóstico e Investigação de Hipertermia Maligna) e Professora Adjunta da Escola Paulista de Medicina (EPM), Universidade Federal de São Paulo (UNIFESP). São Paulo-SP, Brasil.
\end{abstract}

\begin{abstract}
Resumo
Introdução. Hipertermia Maligna (HM) é doença farmacogenética, desencadeada pela exposição de indivíduos susceptíveis a anestésicos voláteis e succinilcolina. Excepcionalmente, crises são desencadeadas por exercício e calor ambiental. Esse estado hipermetabólico manifesta-se por hipercapnia, taquicardia, rigidez muscular, acidose lática e hipertermia; sem tratamento específico, mortalidade alcança 70-80\%. Fora da crise, geralmente o paciente é assintomático, mas raramente apresenta intolerância ao esforço, cãibras musculares ou sinais de miopatia. Artigos/livros e sites informam profissionais de saúde e leigos sobre diagnóstico de HM com teste de contratura muscular in vitro e genética, além do tratamento da crise de HM com dantrolene, mas não estão disponíveis informações para período intercrítico. Objetivo. Elaboração de manual de orientações para os susceptíveis à HM, quanto aos cuidados na vida diária. Método. O manual de orientações fundamentou-se em revisão bibliográfica sobre repercussões da susceptibilidade à HM, realizada segundo diretrizes do QUORUM e do Grupo de Trabalho de Medicina Baseada em Evidências. Resultados. A revisão localizou 129 artigos que foram analisados e permitiram a elaboração de 14 perguntas relacionadas a cuidados com exercício, diagnóstico pré-natal, manejo de doenças associadas pré-existentes (diabetes mellitus, asma brônquica), intoxicações exógenas, drogas ilícitas, tratamento odontológico, e medicações (serotoninérgico, quinolona, anti-dislipidêmico, contraste iodado, inibidor de fosfodiesterase III, bloqueador de canal de cálcio, betabloqueador, neuroléptico, heparina). As informações foram vertidas para linguagem leiga e usadas no manual de orientação disponibilizado online (www.cedhima.unifesp.br). Conclusão. Apesar da HM ser conhecida pela crise anestésica, há implicações na vida diária que devem ser divulgadas para pacientes e profissionais de saúde.
\end{abstract}

Unitermos. Hipertermia Maligna; Educação em Saúde; Prevenção

\begin{abstract}
Introduction. Malignant Hyperthermia $(\mathrm{MH})$ is a pharmacogenetic disease triggered by exposure of susceptible individuals to volatile anesthetics and succinylcholine. Exceptionally, crises are triggered by environmental heat and exercise. This hypermetabolic state manifests as hypercapnia, tachycardia, muscle rigidity, lactic acidosis, and hyperthermia; without specific treatment, mortality reaches $70-80 \%$. On daily life, the patient is usually asymptomatic, but rarely has exercise intolerance, muscle cramps, or signs of myopathy. Articles/books and websites inform health professionals and laypeople about $\mathrm{MH}$ diagnosis with the in vitro muscle contracture test and genetics, in addition to the treatment of $\mathrm{MH}$ crisis with dantrolene, but information is not available for the intercritical period. Objective. Elaboration of a guidance manual for $\mathrm{MH}$ susceptible patients, regarding care in daily life. Method. The guidelines manual was based on a literature review on the repercussions of susceptibility to $\mathrm{MH}$, carried out according to the guidelines of the QUORUM and the Evidence-Based Medicine Working Group. Results. The review found 129 articles that were analyzed and allowed the elaboration of 14 questions related to exercise care, prenatal diagnosis, management of pre-existing
\end{abstract}


associated diseases (diabetes mellitus, bronchial asthma), exogenous intoxications, illicit drugs, dental treatment, and medications (serotoninergic agents, quinolone, anti-dyslipidemic, iodinated contrast agent, phosphodiesterase III inhibitor, calcium channel blocker, beta blocker, neuroleptic, heparin). The information was translated into lay person's language and used in the guidance manual available online (www.cedhima.unifesp.br). Conclusion. Although $\mathrm{MH}$ is known for the anesthetic crisis, there are implications in daily life that must be disclosed to patients and health professionals.

Keywords. Malignant Hyperthermia; Health Education; Prevention

\section{Resumen}

Introdución. La hipertermia maligna $(\mathrm{HM})$ es una enfermedad farmacogenética desencadenada por la exposición de personas susceptibles a anestésicos volátiles y succinilcolina. Excepcionalmente, las crisis son provocadas por el calor ambiental. Este estado hipermetabólico se manifiesta como hipercapnia, taquicardia, rigidez muscular, acidosis láctica e hipertermia; sin un tratamiento específico, la mortalidad alcanza el 70-80\%. Fuera de un ataque, el paciente suele estar asintomático, pero rara vez presenta intolerancia al esfuerzo, calambres musculares o signos de miopatía. Los artículos/libros y sitios web informan a los profesionales de la salud y a la gente común sobre el diagnóstico de HM con pruebas de contractura muscular in vitro y genética, además del tratamiento de la crisis de HM con dantroleno, pero no hay información disponible para el período intercrítico. Objetivo. Elaboración de un manual guía para personas susceptibles a HM, en cuanto al cuidado en la vida diaria. Método. El manual de guías se basó en una revisión de la literatura sobre las repercusiones de la susceptibilidad a la HM, realizada de acuerdo con las guías del QUORUM y del Grupo de Trabajo de Medicina Basada en la Evidencia. Resultados. La revisión encontró 129 artículos que fueron analizados y permitió la elaboración de 14 preguntas relacionadas con el cuidado del ejercicio, diagnóstico prenatal, manejo de enfermedades asociadas preexistentes (diabetes mellitus, asma bronquial), intoxicaciones exógenas, drogas ilícitas, tratamiento dental, y medicamentos (serotoninérgico, quinolona, antidislipidémico, agente de contraste yodado, inhibidor de la fosfodiesterasa III, bloqueador de los canales de calcio, bloqueador beta, neuroléptico, heparina). La información se tradujo al lenguaje común y se utilizó en el manual de orientación disponible en línea (www.cedhima.unifesp.br). Conclusión. Aunque la HM es conocida por su crisis anestésica, existen implicaciones en la vida diaria que deben ser divulgadas a los pacientes y profesionales de la salud.

Palabras clave. Hipertermia maligna; Educación para la salud; Prevención

Trabalho realizado na Universidade Federal de São Paulo, São Paulo-SP, Brasil.

\section{INTRODUÇÃO}

\section{Hipertermia Maligna (HM) é doença farmacogenética,} desencadeada pela exposição de indivíduos susceptíveis a anestésicos voláteis e ao relaxante muscular despolarizante succinilcolina, e raramente por esforço físico e calor ambiente. Exposição a esses agentes resulta em estado hipermetabólico, manifestado clinicamente por hipercapnia, 
taquicardia, contratura de músculo esquelético, acidose lática e hipertermia; sem tratamento específico, mortalidade chega a 70-80\%. HM tem incidência de 1 para 10.00050.000 eventos anestésicos e associa-se com mutações que influenciam a excitação-contração, particularmente com a isoforma esquelética do canal de cálcio do retículo sarcoplasmático, ou receptor rianodina $(R y R 1)^{1}$.

Fora da crise, na sua vida diária, geralmente o paciente não apresenta evidências de doença ou, no máximo, apresenta sinais de miopatia que se expressa clinicamente por hipotonia congênita ou fraqueza muscular de início tardio; ocasionalmente os pacientes apresentam intolerância ao esforço, ou cãibras musculares. Por outro lado, a miopatia congênita central core também é causada por mutações no receptor rianodina ${ }^{1}$.

Informações sobre o diagnóstico de HM com teste de contratura muscular in vitro (TCIV) e genética, além do tratamento da crise de HM com dantrolene estão disponíveis para os profissionais de saúde e leigos em artigos/livros e sites tais como, no Brasil, o site do CEDHIMA (Centro de Estudos Diagnóstico e Investigação da Hipertermia Maligna: https://cedhima.unifesp.br), na Europa no site do Grupo Europeu de Hipertermia Maligna (emhg.org) ou nos EUA no site da MHAUS (Malignant Hypertermia Association of the United States: https://mhaus.org).

Entretanto não há disponibilidade de publicações especializadas e, nem mesmo, material informativo para os susceptíveis à HM, quanto aos cuidados na vida diária. Essa 
lacuna motivou este estudo, com revisão da bibliografia sobre HM com o objetivo de elaboração de manual de orientações para os susceptíveis à HM, quanto aos cuidados na vida diária.

\section{MÉTODO}

O desenvolvimento do manual de orientações fundamentou-se em revisão de literatura, realizada segundo diretrizes do QUORUM e do Grupo de Trabalho de Medicina Baseada em Evidências ${ }^{2,3}$.

O QUORUM refere-se originalmente a pesquisas clínicas controladas e randomizadas, mas também fornece sugestões para revisão sistemáticas. Assim, os artigos foram avaliados quanto aos seguintes critérios: design do estudo, combinabilidade, controle de bias, análise estatística, análise de sensibilidade, problemas de aplicabilidade, busca de evidências, tomada de decisão sobre evidências a incluir, descrição de características de estudos primários, síntese de dados qualitativos, questões relacionadas com a confiabilidade interna (ou qualidade) e implicações clínicas relatadas com a validade externa ou generalizabilidade ${ }^{2}$.

O Grupo de Trabalho de Medicina Baseada em evidências classifica os artigos científicos em 5 níveis: 1) Revisão Sistemática de estudos randomizados; 2) Ensaios clínicos randomizados; 3) Estudos de coorte controlados não randomizados, 4) Séries de casos e estudos casos-controle, e 5) Opinião de especialistas e consenso (raciocínio baseado em mecanismo) ${ }^{3}$. 
O descritor usado foi "Hipertermia Maligna" (Malignant Hyperthermia). Foram realizadas buscas por estudos que avaliassem efeitos de fatores externos em pacientes susceptíveis à HM. Essas buscas incluíram o Medical Literature Analysis and Retrival System Online (MEDLINE) e a Literatura Latino-Americana e do Caribe em Ciências da Saúde (LÍLACS) de 1966 a 2006 inicialmente, as bibliografias dos artigos encontrados e resumos de conferências à procura de estudos em todas as línguas.

Dentre os 4.345 artigos disponíveis no PUBMED e os 95 do LILACS, foram selecionados 25 com aspectos relacionados à prevenção na vida diária, sendo 11 estudos experimentais e 14 clínicos. A partir desses 25 artigos, foram ainda selecionados 97 artigos das suas respectivas bibliografias (Figura 1). Os estudos selecionados incluíram os efeitos de medicamentos, poluentes ambientais e atividade física. Esses estudos incluíam tanto ensaios aleatórios quanto observacionais, em idiomas inglês, francês, alemão e japonês.

Dois autores (GR e HCAS) analisaram independentemente todos os registros (inicialmente um título e resumo) e concordaram na seleção final. Discordâncias entre julgamentos individuais foram resolvidas entre os autores. 
Figura 1. Fluxograma da seleção de artigos.

\begin{tabular}{|c|}
\hline $\mathbf{I}$ \\
$\mathbf{d}$ \\
$\mathbf{e}$ \\
$\mathbf{n}$ \\
$\mathbf{t}$ \\
$\mathbf{i}$ \\
$\mathbf{f}$ \\
$\mathbf{i}$ \\
$\mathbf{c}$ \\
$\mathbf{a}$ \\
$\mathbf{c}$ \\
$\mathbf{a}$ \\
$\mathbf{o}$ \\
\hline
\end{tabular}

\begin{tabular}{|l|}
\hline $\mathbf{T}$ \\
$\mathbf{r}$ \\
$\mathbf{i}$ \\
$\mathbf{a}$ \\
$\mathbf{g}$ \\
$\mathbf{e}$ \\
$\mathbf{m}$ \\
\hline
\end{tabular}

\begin{tabular}{|l|}
\hline E \\
I \\
e \\
g \\
i \\
b \\
i \\
I \\
i \\
d \\
a \\
d \\
e
\end{tabular}

\begin{tabular}{|l|}
\hline I \\
n \\
c \\
I \\
u \\
í \\
d \\
o \\
s \\
\hline
\end{tabular}
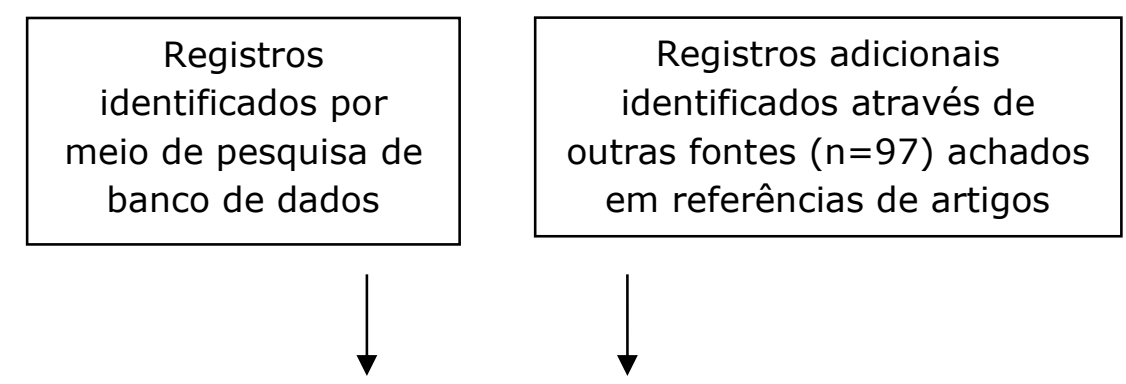

Registros após a remoção de duplicatas

$(n=4.536)$
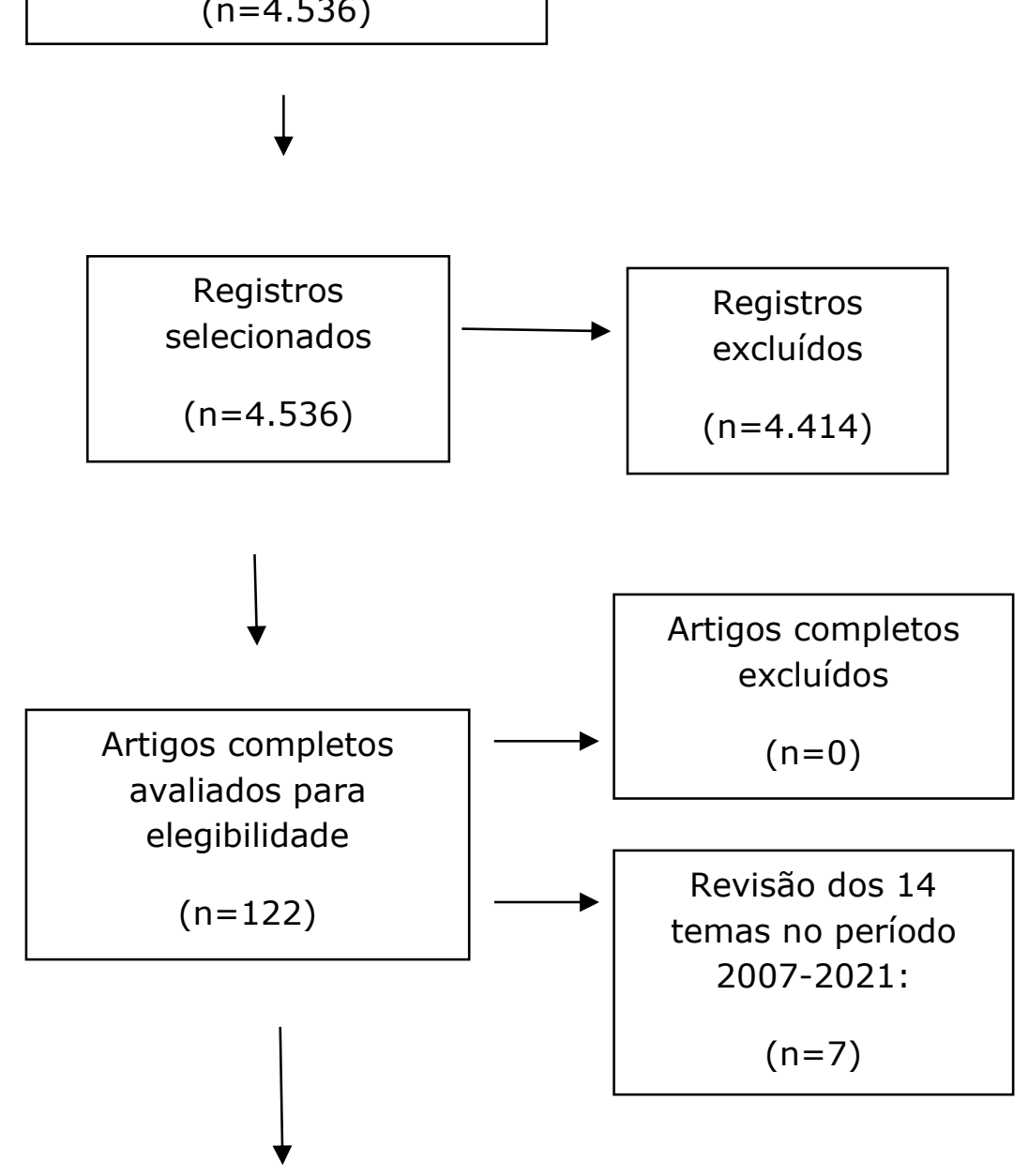

Estudos incluídos em síntese qualitativa

$$
(n=129)
$$


A revisão dos 122 artigos selecionados permitiu a elaboração de 14 perguntas relacionadas a questionamentos levantados ao longo do tempo quanto ao cuidado na vida diária a ser tomado por pacientes susceptíveis à HM. Essas 14 perguntas serão apresentadas em tópicos na seção de resultados, quando disponível referindo os respectivos artigos sobre fundamentos experimentais, as evidências clínicas, o possível impacto na vida diária do paciente e a recomendação final. Como não é ético submeter pacientes com HM a possíveis agentes desencadeantes, muitas pesquisas foram realizadas apenas em modelos animais e em tecidos, principalmente músculo e linfócitos, in vitro.

A partir dessas 14 perguntas, foi elaborado manual de orientações de acordo com os conteúdos clínicos validados por especialistas em HM, seguido de confecção e definição de design. O manual foi confeccionado de acordo com o modelo de elaboração de material educativo em saúde, tendo em vista os aspectos indicados para o desenvolvimento de conteúdo educativo: linguagem adequada para melhor compreensão, ilustração para possibilitar a fixação do conteúdo e layout adequados para aumentar a qualidade e eficiência do manual ${ }^{4-8}$. Seu título foi "Hipertermia Maligna - Manual de Orientação", com oito seções distribuídas em 15 páginas, organizadas por componentes pré-textuais (capa, ficha catalográfica, identificação, sumário e apresentação), textuais (introdução, informações sobre HM, temperatura corporal, tecido muscular, contração muscular, fisiopatologia, diagnóstico, 
tratamento e dúvidas frequentes) e pós-textuais (referências bibliográficas e contatos do CEDHIMA). A apresentação traz informações sobre missão, visão e valores do CEDHIMA e a importância da leitura para o conhecimento da HM. O manual foi elaborado para utilização em meio eletrônico, além da possibilidade de impressão.

Esse manual e a revisão da literatura que lhe serviu de base foram mantidos em sigilo devido à sua utilização em projeto de pesquisa caso-controle para avaliação do seu impacto na melhoria de conhecimento sobre HM. As recomendações foram confrontadas com os artigos publicados em cada tema de 2007 a 2021 ( $n=7)$, e a última revisão ampla de $\mathrm{HM}$, e continuaram adequadas ${ }^{1}$.

\section{RESULTADOS E DISCUSSÃO}

\section{Há risco no uso de medicamentos serotoninérgicos?}

Há aumento dos níveis séricos de serotonina em porcos com HM induzida por halotano. Em animais, o DOI, agonista do receptor serotonina (subtipos 5-HT 2A/2C), induz crise de $\mathrm{HM}$, bem como antagonistas desses receptores (ritanserina) previnem atenuam crise induzida por agonistas da serotonina; entretanto, esses mesmos antagonistas não seriam tão efetivos na crise induzida por halogenados e succinilcolina9-13. Ação da serotonina na HM resultaria da possível ativação, via receptor serotonina, do metabolismo do inositol-1,4,5-trifosfato, que por sua vez aumentaria a liberação de cálcio no músculo esquelético ${ }^{14}$. 
Há cinco artigos relacionados ao tema, classificados como relato de caso ( 1 artigo) e estudos de série de casoscontroles (4 artigos, nível de evidência 4; Tabela 1).

Gener et al. relatam menino com 5 anos e histórico de HM aos 3 anos em cirurgia de orquipexia e anestesia com sevoflurano, tratado com dantrolene, que apresentava dismorfismo (ptose unilateral, criptorquidismo, fácies hipotônica, boca aberta, genovaro e escoliose) e miopatia minicore. Foi hospitalizado por vômitos e dores abdominais, temperatura $37,2^{\circ} \mathrm{C}, \mathrm{FC} 108 \mathrm{bpm}$ e PA $110 \times 63 \mathrm{mmHg}$, exame físico sem alterações. Medicado apenas com Ondansetron $2 \mathrm{mg}$ sublingual e três horas após apresentou rigidez muscular e hipertermia $41^{\circ} \mathrm{C}$, retornando ao hospital em assistolia, sendo realizado reanimação cardiopulmonar sem sucesso; exames laboratoriais indicaram rabdomiólise e hipercalemia. Esse episódio de HM teria resultado do ondansetron que, por ser antagonista do receptor de serotonina subtipo $5 \mathrm{HT} 3$, paradoxalmente leva a um aumento do agonismo dos receptores de serotonina subtipo $2 A^{15}$.

Séries de casos-controles, de forma semelhante ao encontrado em animais, mostram que os agonistas do receptor serotonina induzem contraturas mais precoces e maiores em susceptíveis à HM (MHS: malignant hypertermia susceptible) do que em controles, além de intensificar as contraturas desencadeadas por halotano em MHS. Após estímulo com serotonina, tanto dantrolene como ritanserina inibem as contraturas em não-susceptíveis à HM (MHN: 
malignant hyperthermia negative) e diminuem/retardam aquelas em MHS. Adicionalmente, ritanserina foi capaz de diminuir contraturas desencadeadas por halotano.

Tabela 1. Séries de casos-controles em HM: Inibidores de recaptação de serotonina.

\begin{tabular}{|l|l|l|l|l|}
\hline Autor & $\begin{array}{l}\text { No de } \\
\text { pacientes }\end{array}$ & $\begin{array}{l}\text { Diagnóstic } \\
\text { o } \\
\text { IVCT }\end{array}$ & $\begin{array}{l}\text { Experimento/ } \\
\text { exposição do músculo }\end{array}$ & $\begin{array}{l}\text { Resultados } \\
\text { com músculos in vitro }\end{array}$ \\
\hline $\begin{array}{l}\text { Wappler } \\
1996^{14}\end{array}$ & 40 & $\begin{array}{l}23 \mathrm{MHS} \\
17 \mathrm{MHN}\end{array}$ & $\begin{array}{l}\text { DOI isolado ou com } \\
\text { halotano/concentração } \uparrow \text { por } \\
120 \text { min }\end{array}$ & $\begin{array}{l}\text { DOI: contratura precoce MHS, } \\
\text { contratura MHS > MHN } \\
\text { DOI+Halotano: } \\
\text { MHS contratura > halotano } \\
\text { isolado }\end{array}$ \\
\hline $\begin{array}{l}\text { Wappler } \\
1997^{16}\end{array}$ & 25 & $\begin{array}{l}12 \mathrm{MHS} \\
13 \mathrm{MHN}\end{array}$ & $\begin{array}{l}\text { DOI sem e com pré-incubação } \\
\text { com dantrolene } \\
\text { por } 120 \text { min }\end{array}$ & $\begin{array}{l}\text { DOI: contratura precoce MHS, } \\
\text { contratura MHS > MHN }\end{array}$ \\
\hline $\begin{array}{l}\text { Wappler } \\
1997^{17}\end{array}$ & 41 & $\begin{array}{l}21 \mathrm{MHS} \\
20 \mathrm{MHN}\end{array}$ & $\begin{array}{l}\text { DOI sem e com pré-incubação } \\
\text { com ritanserina por } 120 \text { min } \\
\text { retarda contraturas MHS e inibe } \\
\text { MHN } \\
\text { MHS contratura < DOI isolado }\end{array}$ & $\begin{array}{l}\text { DOI: contratura precoce MHS, } \\
\text { contratura MHS > MHN }\end{array}$ \\
& $25 \mathrm{MHS}$ & $\begin{array}{l}\text { Ritanserina+DOI: retarda } \\
\text { contraturas em MHS e inibe em } \\
\text { com ritanserina por 10 min } \\
\text { MHN } \\
\text { MHS contratura < DOI isolado }\end{array}$ \\
\hline $\begin{array}{l}\text { Wappler } \\
199918\end{array}$ & 25 & $\begin{array}{l}\text { Ritanserina: } \downarrow \text { a contratura pós } \\
\text { halotano }\end{array}$ \\
\hline
\end{tabular}

IVCT - Teste de Contratura Muscular In Vitro, MHS - Suscetível à Hipertermia Maligna, MHN - Hipertermia Maligna Negativo.

Esses trabalhos mostram possível participação do sistema serotoninérgico no desenvolvimento da crise de HM. Entretanto, indivíduos que têm indicação médica para uso de inibidores de recaptação de serotonina são geralmente aqueles cujos níveis de serotonina no SNC estão diminuídos, e a medicação torna-se necessária para aumentar disponibilidade desse neurotransmissor na fenda sináptica ${ }^{19}$. Porém, seu uso poderia teoricamente potencializar o desenvolvimento da crise de HM se houvesse exposição 
concomitante aos agentes desencadeantes halogenados ou succinilcolina em indivíduos que desconhecem ser susceptíveis à HM, levando a crises mais graves. Esse mecanismo poderia explicar a variabilidade de apresentação da crise de HM, de formas leves a fulminantes.

Músculo de pacientes MHS apresentaram contratura quando expostos a ondansetron, mas somente em doses supraterapêuticas ${ }^{20}$. Assim, em relação aos pacientes sabidamente susceptíveis à $\mathrm{HM}$, seria necessário usar com cautela os antagonistas do receptor de serotonina subtipo 5HT3, como ondansetron ${ }^{1}$.

\section{Há risco no uso de antibióticos do grupo quinolona?}

Fluoroquinolonas (FQ) inibem síntese de DNA e são utilizadas para tratamento de infecções bacterianas. Quinolonas de primeira geração são o ácido nalidíxico e o ácido pipemídico. A incorporação de um átomo de flúor na sexta posição caracteriza as $F Q$, que podem ser de segunda geração (norfloxacino), de terceira geração (ciprofloxacino, ofloxacino e levofloxacino) e de quarta geração (moxifloxacino $)^{21}$. Exposição de músculo de porcos MHS a quinolonas levam a contraturas ${ }^{22}$. Há relatos de mialgia e artralgia associadas ao uso de quinolonas, além de ruptura de tendão com alterações da atividade mitocondrial do tenócito.

Foi encontrado um artigo relacionado ao tema, classificado como estudo de caso-controle em humanos, com nível de evidência 4. 
Três pacientes com mialgia, fraqueza, hiperalgia, tendinopatia e artralgia após tratamento com FQ (no início dos sintomas, duas semanas, e 10 meses depois) foram comparados com três indivíduos normais que usaram FQ por 10 dias sem queixas e nove sem uso de $F Q$ e sem mialgia. Todos os três pacientes tinham aumento de creatinoquinase (CK), dois haviam tido rabdomiólise e um apresentou IVCT positivo e hipotrofia das fibras do tipo II e alterações mitocondriais na biopsia muscular. Estudos com ressonância magnética por espectroscopia de fósforo ( $P^{31} M R S$ ) não detectaram anomalias metabólicas em nenhum dos três grupos $^{23}$.

Os efeitos negativos registrados nos três pacientes provavelmente estão relacionados à anomalia muscular préexistente revelada pelo tratamento com $F Q$, sugerindo cautela na sua utilização em indivíduos susceptíveis à HM.

\section{Há risco no exercício?}

Associação entre HM e choque por calor (heatstroke) foi reconhecida pela primeira vez em 1980, em soldado de 19 anos que, durante percurso de marcha, perdeu consciência e apresentou hipertermia (temperatura retal $42^{\circ} \mathrm{C}$ ), acidose metabólica, mioglobinúria, e coagulação intravascular disseminada, com hemorragia intestinal. Foi administrado dantrolene intravenoso e houve melhora em uma hora, com retorno ao normal em poucos dias. Após dois meses sua $\mathrm{CK}$ sérica foi normal e o IVCT positivo ${ }^{24}$. 
Foram analisados 17 artigos, sendo cinco estudos de caso (Tabela 2), nove estudos de série de casos (nível de evidência 4) (Tabela 3), um estudo de caso-controle (nível de evidência 4) e duas revisões com opiniões de especialistas (nível de evidência 5).

Entre séries de casos e relatos de casos, há 166 pacientes com história de hipertermia de esforço submetidos à investigação para HM, dos quais três $(1,8 \%)$ foram a óbito, 88 (53\%) foram considerados susceptíveis pelo IVCT e quatro $(2,4 \%)$ pelo estudo genético (Tabelas 2 e 3 ).

Em estudo de caso controle com nove MHS e nove controles para verificar aumento de temperatura durante atividade física padronizada, houve aumento da temperatura central apenas nos pacientes $\mathrm{MHS}^{38}$.

Hayward et al. sugeriram relação da hipertermia de esforço com alto índice de massa corpórea à custa de massa muscular ${ }^{39}$.

Porter (2003) sugere que indivíduos com história de acidente relacionado ao exercício que apresentam algum outro fator de risco, tais como rabdomiólise por esforço ou choque de calor prévio, devem ser avaliados quanto à susceptibilidade à HM. Para esse autor, é provável que HM e alguns casos de EHI (exertional heat illness) estejam ligados por uma característica genética comum, mas não é possível estimar o risco relacionado, isto é, a proporção de MHS que tem risco de EHI se realizarem exercícios físicos extenuantes e a proporção de pacientes com história de EHI que tem risco de desencadear HM quando expostos à anestesia geral ${ }^{40}$. 
Tabela 2. Problemas relacionados ao exercício e investigação: séries de casos.

\begin{tabular}{|c|c|c|c|c|}
\hline Autor & $\begin{array}{l}\text { População } \\
\text { Atividade }\end{array}$ & $\begin{array}{l}\text { Número de } \\
\text { Pacientes }\end{array}$ & \begin{tabular}{|l} 
Teste \\
Diagnóstico
\end{tabular} & Resultados \\
\hline $\begin{array}{l}\text { Figarella-Branger } \\
1993^{25}\end{array}$ & $\begin{array}{l}\text { Choque de calor } \\
\text { exercício }\end{array}$ & 45 & IVCT & $\begin{array}{l}11 \mathrm{MHS} \\
6 \mathrm{HMC} \\
2 \mathrm{HMh} \\
26 \mathrm{MHN}\end{array}$ \\
\hline $\begin{array}{l}\text { Bendahan } \\
2001^{26}\end{array}$ & $\begin{array}{l}\text { Choque de calor } \\
\text { exercício }\end{array}$ & 26 & $\begin{array}{l}\text { IVCT } \\
\text { 31P MRS }\end{array}$ & $\begin{array}{l}19 \mathrm{MHS} \\
7 \mathrm{MHN}\end{array}$ \\
\hline $\begin{array}{l}\text { Wappler } \\
2001^{27}\end{array}$ & $\begin{array}{l}\text { Rabdomiólise } \\
\text { treinamento militar }\end{array}$ & 12 & \begin{tabular}{|l} 
IVCT \\
Genética RYR
\end{tabular} & $\begin{array}{l}10 \text { MHS } \\
2 \text { MHN } \\
03 \text { RYR }\end{array}$ \\
\hline $\begin{array}{l}\text { Davis } \\
2002^{28}\end{array}$ & \begin{tabular}{|l|}
$\uparrow C K$ \\
dores/cãibras \\
exercícios \\
$\uparrow C K$ \\
cãibras \\
exercícios
\end{tabular} & $\begin{array}{l}01 \\
03 \\
\text { pai-2 filhos }\end{array}$ & $\begin{array}{l}\text { IVCT } \\
\text { IVCT }\end{array}$ & $\begin{array}{l}01 \mathrm{MHS} \\
01 \mathrm{MHS} \\
02 \mathrm{HMe}\end{array}$ \\
\hline $\begin{array}{l}\text { Kozak-Ribbens } \\
1994^{29}\end{array}$ & Choque de calor & 55 & IVCT & $\begin{array}{l}06 \mathrm{MHS} \\
13 \mathrm{HMe} \\
36 \mathrm{MHN}\end{array}$ \\
\hline $\begin{array}{l}\text { Denborough } \\
1998^{30}\end{array}$ & \begin{tabular}{|l} 
Rabdomiólise \\
Squach/álcool \\
Cefaléia/vertigens \\
Náuseas/fadiga \\
esforço \\
Choque de calor \\
exercícios de combate \\
Rabdomiólise \\
Sprint
\end{tabular} & $\begin{array}{l}03 \\
02 \\
\text { pai-filho } \\
01\end{array}$ & $\begin{array}{l}\text { IVCT } \\
\text { IVCT } \\
\text { IVCT } \\
\text { IVCT }\end{array}$ & $\begin{array}{l}03 \text { MHS } \\
02 \text { MHS } \\
\text { MHS } \\
\text { MHS }\end{array}$ \\
\hline $\begin{array}{l}\text { Hackl } \\
1991^{31}\end{array}$ & $\begin{array}{l}\text { Febre/miólises } \\
\text { exercícios }\end{array}$ & 02 & IVCT & $\begin{array}{l}01 \mathrm{MHS} \\
01 \mathrm{MHN}\end{array}$ \\
\hline $\begin{array}{l}\text { Holpkins } \\
1991^{32}\end{array}$ & $\begin{array}{l}\text { Choque de calor } \\
\text { treinamento militar }\end{array}$ & $\begin{array}{l}2 \text { famílias } \\
2 \text { pais-2 filhos }\end{array}$ & IVCT & $\begin{array}{l}02 \text { MHS pais } \\
02 \text { MHN filhos }\end{array}$ \\
\hline $\begin{array}{l}\text { Watson } \\
2000^{33}\end{array}$ & \begin{tabular}{|l|} 
Rabdomiólises \\
treinamento militar
\end{tabular} & 02 & IVCT & $\begin{array}{l}01 \text { MHS } \\
01 \text { MHN }\end{array}$ \\
\hline
\end{tabular}

MHS- Suscetível à Hipertermia Maligna, HMc- Suscetível à Hipertermia Maligna após resposta com Cafeína, HMe- Hipertermia Maligna Equívoco: suscetível à Hipertermia Maligna após resposta com apenas uma droga, seja cafeína ou halotano; HMh- suscetível à Hipertermia Maligna após resposta com Halotano, MHNHipertermia Maligna Negativo, IVCT- Teste de Contratura Muscular In Vitro, RYR- Gene Rianodina; 31PMRS: espectroscopia de fósforo 
Tabela 3. Problemas relacionados ao exercício e investigação: Relatos de caso.

\begin{tabular}{|l|l|l|l|l|}
\hline Autor & $\begin{array}{l}\text { População } \\
\text { Atividade }\end{array}$ & $\begin{array}{l}\text { Número de } \\
\text { pacientes }\end{array}$ & $\begin{array}{l}\text { Teste } \\
\text { Diagnóstico }\end{array}$ & Resultados \\
\hline $\begin{array}{l}\text { Denborough } \\
1982^{24}\end{array}$ & $\begin{array}{l}\text { Choque de calor } \\
\text { marcha militar }\end{array}$ & 01 & IVCT & MHS \\
\hline $\begin{array}{l}\text { Pamukcoglu } \\
1988^{34}\end{array}$ & $\begin{array}{l}\text { Morte súbita } \\
\text { atleta jovem }\end{array}$ & 01 pai & IVCT & MHS \\
\hline $\begin{array}{l}\text { Ryan } \\
1997^{35}\end{array}$ & $\begin{array}{l}\text { Parada } \\
\text { cardíaca/ } \\
\text { rigidez } \\
\text { exercícios } \\
\text { físicos } \\
\text { moderados }\end{array}$ & 01 & $\begin{array}{l}\text { História familiar } \\
\text { MHS }\end{array}$ & óbito \\
\hline $\begin{array}{l}\text { Köchling } \\
1998^{36}\end{array}$ & $\begin{array}{l}\text { Choque de calor } \\
\text { rabdomiólise } \\
\text { exercícios } \\
\text { físicos } \\
\text { extenuante }\end{array}$ & 01 & IVCT & MHS \\
\hline $\begin{array}{l}\text { Tobin } \\
2001^{37}\end{array}$ & $\begin{array}{l}\text { HMA } \\
\text { HMe } \\
\text { futebol }\end{array}$ & 01 & DNA & Óbito \\
RYR +
\end{tabular}

DNA- Ácido Desoxirribonucleico; HMA- Hipertermia Maligna Anestésica; HMe- Hipertermia Maligna Equívoco: suscetível à Hipertermia Maligna após resposta com apenas uma droga, seja cafeína ou halotano; MHS- Suscetível à Hipertermia Maligna; IVCT- Teste de Contratura Muscular In Vitro; RYR- Gene Rianodina

Contudo, a possibilidade de semelhante ligação é preocupante e deve ser conhecida pelos anestesistas do serviço médico.

Há necessidade de cautela no exercício para pacientes susceptíveis à $\mathrm{HM}$, os quais devem ser advertidos no sentido de se precaverem, no que diz respeito ao serviço militar e esportes como squash, sprint, maratonas e mesmo jogos de futebol. Sugere-se que todo paciente suscetível porte identificação com as informações sobre HM, desse modo esses pacientes devem ser dispensados do serviço militar bem como evitar esforços físicos extenuantes e profissões exercidas em altas temperaturas ambientes ${ }^{41}$. 


\section{Há risco no uso de medicações para baixar o colesterol?}

Tratamento antidislipidêmico com estatinas pode induzir mialgia grave, aumento de CK e rabdomiólise em indivíduos normais; essas alterações musculares enquadram-se nas miopatias dos agentes redutores do colesterol (MARC ou CLAM). No entanto, a patogênese desse quadro clínico de miotoxidade ainda é controversa. Postulase que estatinas podem modificar o processo de excitaçãocontração, por ação no retículo sarcoplasmático, com resultante aumento dos níveis intracelulares de cálcio ${ }^{42,43}$. Complicações musculares relacionadas ao uso de estatinas já foram relatadas em pacientes MHS, além disso, possível crise de HM ocorreu em pacientes usando estatinas.

Foram analisados quatro artigos classificados como: um relato de caso, dois estudos de série de casos (nível de evidência 4) e uma opinião de especialista (nível de evidência $5)$.

$\mathrm{Na}$ análise conjunta dos relatos de casos com confirmação, há 12 pacientes com história de MARC, submetidos à investigação para HM, dos quais $10(83,3 \%)$ foram considerados susceptíveis pelo IVCT (Tabela 4). Estudos revelam ainda a investigação através do IVCT em quatro familiares de um paciente com história de MARC, todos MHS.

Há relatos em que há suspeitas de efeitos adversos durante cirurgias pelo uso de estatinas e fibratos, e possível susceptibilidade à $H M$, porém os pacientes não foram 
investigados com o TCHC (teste de contratura halotanocafeína) ${ }^{44,45}$.

Tabela 4: Relatos de caso da associação uso estatinas e HM.

\begin{tabular}{|c|c|c|c|c|c|}
\hline Autor & População & Idade & Droga & Teste diagnóstico & Resultado \\
\hline $\begin{array}{l}\text { Guis } \\
2003^{46}\end{array}$ & $\begin{array}{l}\text { mialgia } \\
\text { rabdomiólises } \\
\text { mioglobinúria }\end{array}$ & $51 a$ & Atorvastatina & \begin{tabular}{|l} 
IVCT \\
6 meses \\
após retirada da \\
droga \\
CK normal
\end{tabular} & MHS \\
\hline $\begin{array}{l}\text { Krivosic-Horber } \\
2004^{47}\end{array}$ & $\begin{array}{l}\text { cãibras } \\
\text { fadiga } \\
\uparrow C K \\
\\
\text { cãibras } \\
\text { fadiga } \\
\uparrow C K\end{array}$ & $\begin{array}{l}44 a \\
49 a\end{array}$ & $\begin{array}{l}\text { Atorvastatina } \\
\text { Cerivastatina } \\
\text { Atorvastatina }\end{array}$ & $\begin{array}{l}\text { IVCT } \\
34 \text { meses após } \\
\text { retirada da droga } \\
4 \text { familiares } \\
\text { IVCT } \\
12 \text { meses após } \\
\text { retirada da droga }\end{array}$ & $\begin{array}{l}\text { MHS } \\
04 \text { MHS } \\
\text { MHS }\end{array}$ \\
\hline $\begin{array}{l}\text { Guis } \\
2006^{48}\end{array}$ & \begin{tabular}{|l} 
Mialgia \\
$\uparrow$ CK \\
biopsia 6 \\
meses após \\
interrupção \\
estatina
\end{tabular} & $\begin{array}{l}55 a \\
57 a \\
66 a \\
75 a \\
58 a \\
52 a \\
42 a \\
58 a \\
50 a\end{array}$ & $\begin{array}{l}\text { Atorvastatina } \\
\text { Sinvastatina } \\
\text { Atorvastatina } \\
\text { Cerivastatina } \\
\text { Pravastatina } \\
\text { Atorvastatina } \\
\text { Fluvastatina } \\
\text { Sinvastatina } \\
\text { Sinvastatina- } \\
\text { Atorvastatina }\end{array}$ & $\begin{array}{l}\text { IVCT } \\
\text { IVCT } \\
\text { IVCT } \\
\text { IVCT } \\
\text { IVCT } \\
\text { IVCT } \\
\text { IVCT } \\
\text { IVCT } \\
\text { IVCT }\end{array}$ & $\begin{array}{l}\text { MHS } \\
\text { MHEh } \\
\text { MHEc } \\
\text { MHS } \\
\text { MHEC } \\
\text { MHEC } \\
\text { MHEh } \\
\text { MHN } \\
\text { MHN }\end{array}$ \\
\hline
\end{tabular}

CK- Creatinoquinase, MHS- Suscetível à Hipertermia Maligna, MHEc- Suscetível à Hipertermia Maligna após resposta com Cafeína, MHEh- suscetível à Hipertermia Maligna após resposta com Halotano, MHNHipertermia Maligna Negativo, IVCT- Teste de Contratura Muscular In Vitro

Segundo Katirji et al., a ocorrência isolada de hiperckemia (aumento do CK), é indicação para realização de IVCT para investigar a susceptibilidade genética à $\mathrm{HM}^{49}$. Assim, o subgrupo de pacientes com hiperckemia em uso de estatinas representaria um subgrupo com maior risco de HM.

I. Desenvolvimento de mialgia, hiperckemia, rabdomiólise ou mioglobinúria, em pacientes que fazem uso de estatina, pode sugerir pré-existência 
de doenças neuromusculares ou distúrbios genéticos. Estes indivíduos devem ser encaminhados para exame neurológico, investigação de miopatias e, quando indicado, posterior realização de teste de contratura para verificar a possibilidade de susceptibilidade à HM. Quatro de 360 pacientes com MARC apresentavam variantes no gene rianodina, e $16 \%$ apresentavam variantes nos genes rianodina e di-hidropiridina 50,51 .

II. A homeostase muscular pode ser alterada por estatina e fibratos, interferindo principalmente no cálcio intracelular; deste modo deve-se ter cautela quando essas drogas forem indicadas em pacientes susceptíveis à MHS, monitorizando sintomas e sinais de miopatia, além da CK.

III. Tendo em vista as alterações intracelulares que podem ocorrer em pacientes que usam estatinas, e a possibilidade desses indivíduos com miopatia por estatina serem susceptíveis à $H M$, deve-se ter cautela no uso de halogenados e succinilcolina em cirurgias nesses pacientes.

\section{Há risco em usar contraste iodado?}

Administração do contraste iodado tanto por via intratecal quanto por via endovenosa pode provocar hipertermia, taquicardia, rabdomiólise, acidose, hipercapnia e convulsões, e levar ao óbito ${ }^{52-55}$. 
Foram analisados cinco estudos, classificados como: três relatos de casos e duas opiniões de especialista (nível de evidência 5).

Por suspeita de HM em um dos casos relatados foram utilizadas duas doses de Dantrolene Sódico, mas sem melhora, e o IVCT foi normal ${ }^{53}$. Estes relatos apresentam alguns sinais da crise de HM, porém todos descrevem a presença de movimentos tônicos clônicos que descaracterizam o diagnóstico clínico de HM.

Não há contraindicação para o uso de contraste iodado em pacientes susceptíveis à HM.

\section{6. É possível fazer o diagnóstico do meu filho antes que ele tenha a idade mínima para que possa realizar a biopsia muscular?}

O padrão ouro para pesquisar a susceptibilidade à HM é o teste de contratura muscular. Entretanto, a idade mínima para realizar o IVCT é de 10 anos no protocolo europeu e cinco anos no protocolo norte-americano (TCHC). Contudo, se a história de HM na família foi confirmada pelo IVCT, e a investigação familiar com a genética molecular detectou mutações no receptor rianodina em pessoas que tiveram IVCT positivo, nessa família o diagnóstico genético pode também ser empregado. Alternativamente, pode ser empregado só o teste genético se for encontrada uma das variantes comprovadamente associadas à HM. Para isso é necessário obter material para o estudo genético, através da coleta do sangue venoso periférico ${ }^{56}$. 
Porém, se a família não tem ainda mutação detectada, ou há discordância entre o resultado do IVCT e a detecção de mutação na família, a ausência de mutação não exclui o diagnóstico de susceptibilidade à HM. A HM possui heterogeneidade genética, visto que já foi relacionada a alterações em genes/loci nos cromossomos 19, 17, 7, 5, 3 e 1 , além de outros que estão ainda sendo estudados. Existe ainda a possibilidade da presença de dois genes ligados à HM em algumas famílias ${ }^{57,58}$.

Foram analisados oito estudos, classificados como: um relato de caso, dois relatos de série de casos (nível de evidência 4) e cinco opiniões de especialistas (nível de evidência 5).

Girard et al. relatam um caso de coleta de sangue do cordão umbilical após o nascimento, e posterior análise genética que coincidiu com o resultado obtido anteriormente na mãe e avó materna. Esse estudo enfatiza também a importância de todas as gestantes MHS terem a oportunidade de realizar o teste de seu recém-nascido através da coleta de sangue do cordão umbilical durante o parto, visto ser técnica de fácil execução e não invasiva; para isso é imprescindível à presença de casos de susceptibilidade familiar com o teste genético realizado e a mutação definida. No caso do teste do bebê ser negativo para HM, quando um dos pais for MHS, para excluir com segurança a positividade deve-se realizar posteriormente o $\mathrm{TCHC}^{59,60}$.

Krivosic et al. estudaram 26 crianças entre 02 e 13 anos através de IVCT, em que 14 casos forem testados por 
apresentarem sintomas e 12 por susceptibilidade na família, e tais testes não apresentaram distorções em decorrência da pouca idade dos pacientes ${ }^{61}$.

Stowell relata 23 casos de pesquisa do sangue retirado do cordão umbilical do recém-nascido de famílias MHS, mutações relacionadas à HM em 11 bebês - seis amostras foram idênticas ao genótipo materno e cinco ao paterno. Para aumentar a confiabilidade neste tipo de diagnóstico e excluir a possibilidade de contaminação pelo sangue da mãe, o sangue do bebê com a mesma mutação materna deve ser testado novamente mais tarde ${ }^{62}$.

O teste genético em crianças e idosos, que não possuem grandes áreas musculares, é mais factível e menos invasivo que o TCHC, desde que a família tenha mutação detectada e que seja concordante com o resultado do TCHC $59,63,64$.

\section{Posso usar medicação para o coração?}

Inibidor de PDE-III

Inibidores de fosfodiesterase (PDE) III, como amrinona/enoximona, aumentam o cálcio sarcoplasmático em fibras musculares cardíacas e esqueléticas. Amrinona pode ser empregado pelo anestesiologista para tratamento da insuficiência cardíaca aguda, pois possui efeitos inotrópicos positivos aditivos e sinérgicos quando associado a catecolaminas, além dos seus efeitos vasodilatadores. Devido ao seu amplo espectro farmacodinâmico, amrinona controla todos principais elementos envolvidos no 
desempenho miocárdico: pré e pós contratilidade e frequência cardíaca65,66. Fielge et al. estudaram in vitro amrinona e enoximona em músculo esquelético de suínos MHS e MHN e relataram contratura em músculos de animais MHS em concentrações significativamente menores que nos animais MHN. Ainda em porcos MHS e MHN, a administração in vivo de enoximona em doses cumulativas e consecutivas não provocou crises de HM; mas todos os animais morreram por falência cardiovascular 66,67 .

Foram analisados três estudos, classificados como: um relato de caso e dois relatos de séries de casos (nível de evidência 4).

Riess et al. relatam paciente que desenvolveu sinais clínicos de HM associados a administrações de duas doses de enoximona, uma durante cirurgia com circulação extracorpórea e outra dose três dias após cirurgia cardíaca que ocorreu sem a utilização de agentes desencadeantes. Em ambas as situações foi utilizado dantrolene e paciente evoluiu sem sequelas. Cinco meses após os eventos, realizou TCHC e foi diagnosticado MHS; enoximona foi adicionado ao banho do TCHC e provocou contraturas ${ }^{68}$. Fiege et al. em dois estudos com pacientes MHS e MHN, diagnosticados através do TCHC, adicionou enoximona cumulativamente ao banho e todas as amostras musculares apresentaram contratura; porém contraturas foram mais precoces e mais intensas em músculos de MHS comparadas aos MHN. Os autores alertam sobre o perigo do uso de enoximona em pacientes $\mathrm{MHS}^{69,70}$. 
Apesar do relato de caso de crise de HM em paciente tratado com enoximona, e dessa droga desencadear contraturas em músculos de humanos e porcos susceptíveis, altas doses em porcos não desencadearam HM. Esses estudos sugerem que, apesar de afetar metabolismo do cálcio no músculo esquelético e provocar contraturas, é possível que enoximona isoladamente não seja suficiente para desencadear a crise clínica de HM. Porém é possível que a associação com outros fatores, como estresse cirúrgico e reaquecimento após circulação extracorpórea, permita desencadear a crise de HM; assim, seria prudente evitar enoximona em paciente suscetível à HM submetido a cirurgia.

\section{Bloqueador de canal de cálcio}

Bloqueadores de canal de cálcio (BCC) são usados em doenças cardiovasculares como hipertensão, angina e arritmias, por seus efeitos vasodilatadores, inotrópicos negativos e bradicardizantes. Dentre os BCC disponíveis, três (diltiazem, nicardipina e verapamil) possuem apresentação venosa e podem ser usados para emergências. Há três grupos de BCC: felilalquilaminas (verapamil), benzotiazepínicos (diltiazem), e dihidropiridinas (nifedipina, amlodipina, isradipina $)^{71}$.

Diltiazem diminuiu significativamente a contratura de músculos esqueléticos de porcos susceptíveis à $\mathrm{HM}$ quando testados pelo TCHC com cafeína e halotano, além de cloreto de potássio, provocando resultados falso negativos ${ }^{72,73}$. 
Verapamil e nifedipina inibiram a contração e a contratura induzida por cloreto de potássio, mas não a contratura induzida por cafeína ou halotano em músculos de suínos susceptíveis; esses antagonistas de canais de cálcio poderiam inibir a contração/contraturas via desacoplamento entre excitação (despolarização da membrana) e contração (liberação do $\mathrm{Ca}^{2}{ }^{2}$ do retículo sarcoplasmático) por meio de ação no receptor di-hidropiridina. Além disso, quando verapamil foi administrado com dantrolene, resultou em diminuição da função cardíaca e hipercalemia, induzindo colapso cardiovascular em suínos. O uso concomitante de verapamil e dantrolene também provocou colapso cardiovascular e arritmias em cachorros $^{74-76}$.

Foram encontrados quatro artigos: um classificado como relato de caso e três classificados como relatos de série de casos (nível de evidência 4).

Verapamil foi utilizado no passado para tratamento de arritmias na HM, e até para tratamento da própria crise, conforme descrito em relato de série de casos em que cinco pacientes foram tratados com verapamil durante crise de HM (uso isolado em três, e associado ao dantrolene em dois pacientes): quatro pacientes sobreviveram e um paciente faleceu. Rubin et al. relatam que um paciente com suspeita de susceptibilidade à HM, em uso de verapamil, recebeu dantrolene profilático oral por cinco dias para cirurgia coronariana, desenvolvendo hipercalemia e depressão miocárdica. TCHC não foi feito, mas havia suspeita de susceptibilidade por história pessoal prévia de hipertermia 
em anestesia e história de rigidez muscular em dois netos durante indução de anestesia geral. Esse paciente posteriormente foi submetido a outra cirurgia sem intercorrências, mas tendo o verapamil sido substituído por nifedipina 77,78 .

Adicionalmente, nifedipina aumentou a liberação de cálcio em músculo humano de forma mais intensa em susceptíveis que normais, e com pouca resposta ao uso de dantrolene ${ }^{79}$.

Dezoito pacientes diagnosticados como MHS, conforme o protocolo Europeu, tiveram seus músculos testados no TCHC com adição prévia de bloqueadores de canal de $\mathrm{Ca}^{2}+$, (10 amostras com diltiazem e oito com nifedipina); o bloqueador de canal de cálcio provocou resultados falsonegativos no teste de contratura com halotano em cinco dos dez testados com diltiazem e em cinco dos oito testados com nifedipina ${ }^{80}$.

Tendo em vista as complicações do uso concomitante de verapamil e dantrolene, não é aconselhável a utilização dos bloqueadores de canal de cálcio em associação com dantrolene para tratamento de crise de HM em seres humanos $\mathrm{MHS}^{81}$.

Os bloqueadores de canal de cálcio como diltiazem e nifedipina podem falsear o resultado do TCHC, devendo seu uso ser investigado em consulta médica antes da realização da biópsia para diagnosticar HM. Idealmente, seu uso deveria ser descontinuado antes do TCHC. 
Betabloqueadores

Propranolol é bloqueador beta-adrenérgico não cardiosseletivo usado para o tratamento da angina pectoris, arritmias e hipertensão ${ }^{82}$.

Foi encontrado um artigo classificado como relato de série de casos (nível de evidência 4).

A adição de propranolol ao banho do TCHC em 27 (12 MHS, 12 MHN e 03 MHE) não levou a alterações no teste com halotano, porém a adição do propranolol ao banho da cafeína provocou diminuição na resposta das contraturas musculares dos susceptíveis à $\mathrm{HM}^{83}$.

Uso de propranolol em pacientes a serem investigados através de TCHC deve ser pesquisado para descontinuação antes do teste.

\section{Tenho risco adicional por ser diabético com HM?}

A Síndrome Não Cetótica Hiperosmolar Hiperglicêmica (HHNS) tem alta mortalidade, devido à comorbidades. Moller-Petersen et al., já referiam a rabdomiólise não traumática em cetoacidose diabética, em cinco de 12 pacientes consecutivos. Alguns pacientes que desenvolveram HHNS e Síndrome Semelhante à Hipertermia Maligna, com aumento da temperatura, rabdomiólise e instabilidade cardiovascular, responderam ao uso de dantrolene 84,85 . Nesses casos foram levantadas duas etiologias: associação de deficiência subclínica na acyl-coA desidrogenase de cadeia curta (SCAD) e ação do conservante da insulina 4-m-cloro-cresol. 
A deficiência na SCAD impede que o organismo use ácido graxos de cadeia curta como fonte de energia, levando ainda a acúmulo de amônia. Crianças afetadas apresentam vômitos, hipoglicemia, letargia, hipotonia, convulsões, microcefalia, além de falha em ganhar peso e crescer ao ritmo esperado. Esses sintomas podem ser desencadeados por períodos de jejum ou infecções virais. Entretanto, em alguns casos, esses sintomas podem não aparecer até a idade adulta, quando alguns indivíduos podem desenvolver fraqueza muscular, mas algumas pessoas podem ter sintomas leves que nunca são diagnosticados ${ }^{86}$.

Wappler et al. relatam um estudo realizado com seis porcos Pietrain (MHS) e seis controles (MHN), submetidos à administração de $4 \mathrm{CmC}$ em doses de 12 e $24 \mathrm{mg} / \mathrm{kg}$, em que todos MHS desenvolveram crise de HM e foram tratados com dantrolene com sucesso, sendo que nenhum dos controles desenvolveu sinais compatíveis com HM. Além disso, a insulina, por si só, pode aumentar a concentração intracelular de cálcio em camundongos, o que poderia explicar o aumento do gasto energético em repouso, após estímulo com insulina, evidenciado em pacientes $\mathrm{MHS}^{87,88}$.

Foram analisados quatro estudos, classificados como: dois relatos de casos e dois relatos de série de casos (nível de evidência 4).

Nos dez casos analisados (Tabela 5 ), todos eram jovens (10-23 anos) e havia predomínio de homens (8:1), negros (6) e obesos com acantosis nigricans (6), com início da MHLS (malignant hyperthermia-like syndrome) após o uso de 
insulina (9); em dois casos o dantrolene foi usado com sucesso, e um caso teve diagnóstico positivo para HM pelo TCHC (Tabela 5).

Pacientes com cetoacidose e rabdomiólise devem ser investigados para HM?

Rabdomiólise associada à cetoacidose não é encarada como HM propriamente dita, mas como síndrome semelhante à $\mathrm{HM}$; para essas entidades, medidas de prevenção de HM e teste de contratura são controversas. Entretanto, seria preciso seguir esses pacientes, com avaliação neurológica, pesquisa de miopatia e alteração metabólica subjacente, para esclarecimento dessa situação. É necessário estudo sistemático de maior número de pacientes para responder essa questão. Recentemente, demonstrou-se que susceptibilidade à HM leva a alterações do metabolismo da glicose, levando a hiperglicemia e maior frequência de diabetes mellitus nesses pacientes ${ }^{92}$.

2. Pacientes susceptíveis à HM correm risco com o uso de insulina com clorocresol como aditivo?

A dose de cloro-cresol necessária para induzir crise de HM em porcos foi bem superior àquela presente na insulina como conservante e usada para tratamento da cetoacidose. 
Tabela 5. Relatos de Caso de Síndrome Hiperglicêmica e HM.

\begin{tabular}{|c|c|c|c|c|c|}
\hline $\begin{array}{l}\text { Autor } \\
\text { Ano }\end{array}$ & $\begin{array}{l}\text { Idade/ } \\
\text { Antecedentes }\end{array}$ & Sinais, sintomas e laboratório & Tratamento & Evolução & IVCT \\
\hline $\begin{array}{l}\text { Wappler } \\
1996^{89}\end{array}$ & $\begin{array}{l}22 a, M, 4 \text { dias de } \\
\text { desordens } \\
\text { gastrointestinais }\end{array}$ & $\begin{array}{l}\text { Iniciais: Glicose } 60,27 \mathrm{mmol} / \mathrm{l}, \mathrm{TCU}, \downarrow \\
\text { consciência, desidratação, } \\
\text { taquicardia, hipotensão, acidose. Pós } \\
\text { insulina com m-cresol (1h): mialgia, } \\
\text { hipercapnia, hipertermia, CK } \\
12.848 \mathrm{U} / \mathrm{L}\end{array}$ & $\begin{array}{l}\text { Entubação/VM/resfriamento } \\
\text { hiperventilação,dantrolene, } \\
\text { drogas vasoativas }\end{array}$ & $\begin{array}{l}\text { Alta após } 15 \text { dias } \\
\text { sem sequelas }\end{array}$ & MHS \\
\hline $\begin{array}{l}\text { Holland } \\
\text { er } \\
2003^{90}\end{array}$ & $\begin{array}{l}\text { 18a, M, obeso, } \\
\text { negro, AN } \\
14 a, M \text {, obeso, } \\
\text { negro, AN } \\
16 a, M \text {, obeso, } \\
\text { negro, AN } \\
14 a, M, \text { obeso, } \\
\text { negro, AN } \\
16 a, M, \text { obeso } \\
\text { AN } \\
14 a / M\end{array}$ & $\begin{array}{l}\text { Iniciais: Glicose } 1.810 \mathrm{mg} / \mathrm{dL}, \mathrm{TCU} \\
\text { Tardios: } \\
\text { Febre/choque/rabdomiólise/falência } \\
\text { renal } \\
\text { Iniciais: Glicose } 970 \mathrm{mg} / \mathrm{dL}, \mathrm{TCU} . \\
\text { Tardios: Febre/choque/ } \downarrow \\
\text { consciência/edema cerebral/arritmia } \\
\text { refratária } \\
\text { Iniciais: Glicose } 1.381 \mathrm{mg} / \mathrm{dL}, \mathrm{TCU} \\
\text { Tardios: febre/choque/ } \\
\downarrow \text { consciência/rabdomiólise/falência } \\
\text { renal hipotensão } \\
\text { Iniciais: Glicose } \\
\text { 1.600mg/dL,TCU/êmeses.Tardios:Fe } \\
\text { bre/choque } \downarrow \\
\text { consciência/hipotensão/rabdomiólise } \\
\text { /falência renal } \\
\text { Iniciais: Glicose } 1.680 \mathrm{mg} / \mathrm{dl}, \text { TCU } \\
\text { diarreia/êmeses/falência renal } \\
\text { /febre/hipotensão/letargia. } \\
\text { Tardios:Febre/rabdomiólise/arritmia } \\
\text { ventricular/assistolia } \\
\text { Iniciais: Glicose } 2.580 \mathrm{mg} / \mathrm{dl}, \\
\text { fraqueza/tonturas. Tardios: Febre } \\
\text { hipotensão/ } \downarrow \text { consciência/taquicardia } \\
\text { ventricular/rabdomiólise }\end{array}$ & $\begin{array}{l}\text { Hidratação/insulina } \\
\text { entubação/diálise } \\
\text { Hidratação/insulina } \\
\text { entubação } \\
\text { Hidratação/insulina/diálise } \\
\text { Hidratação/insulina/diálise } \\
\text { Hidratação/insulinoterapia } \\
\text { succinilcolina pré entubação } \\
\text { Hidratação/insulina/ manitol } \\
\text { entubação/cardioversão }\end{array}$ & $\begin{array}{l}\text { Alta após } 104 \\
\text { dias } \\
\text { Óbito sem causa } \\
\text { específica } \\
\text { Parada cardíaca } \\
\text { na cateterização } \\
\\
\text { \função cardíaca } \\
\text { edema pulmonar } \\
\text { óbito após } 4 \text { dias } \\
\text { Óbito após } 13 \mathrm{~h} \\
\text { Necrópsia: sem } \\
\text { cardiopatia } \\
\text { Alta após } 8 \text { dias }\end{array}$ & \\
\hline $\begin{array}{l}\text { Kilbane } \\
2006^{85}\end{array}$ & $\begin{array}{l}\text { 16a, M, obeso, } \\
\text { negro, AN } \\
10 a, F \text {, negra }\end{array}$ & $\begin{array}{l}\text { Iniciais: Glicose } 1.667 \mathrm{mg} / \mathrm{dL} \text {, } \\
\text { êmeses/polidipsia/poliúria/letargia } \\
\text { desidratação /taquicardia. Tardios: } \\
\text { Febre/hipotensão/ } \downarrow \text { nível de } \\
\text { consciência/rabdomiólise/taquicardia } \\
\text { ventricular } \\
\\
\text { Iniciais: Glicose } 1.650 \mathrm{mg} / \mathrm{dL}, \\
\text { êmeses/poliúria/olidipsia/confusão } \\
\text { mental/desidratação/taquicardia. } \\
\text { Tardios: Febre/hipotensão } \downarrow \text { nível de } \\
\text { consciência/rabdomiólise/taquicardia } \\
\text { ventricular }\end{array}$ & $\begin{array}{l}\text { Hidratação/insulina entubação } \\
\text { Hidratação/Dantrolene } \\
\text { insulina/entubação }\end{array}$ & $\begin{array}{l}\text { Óbito após } 13 \mathrm{~h} \\
\text { Necrópsia:hernia } \\
\text { tonsilar,edema } \\
\text { cerebral/SCAD } \\
\text { Alta após } 21 \text { dias } \\
\text { sem sequelas }\end{array}$ & \\
\hline $\begin{array}{l}\text { Baluch } \\
2007^{91}\end{array}$ & $26 a, M$ & $\begin{array}{l}\text { Iniciais: Glicose } 1.194 \mathrm{mg} / \mathrm{dL} \text { - } \\
\text { êmeses/poliuria/polidipsia } \\
\text { desidratação/letargia/dor } \\
\text { epigástrica. Tardios:Febre } \\
\text { rabdomiólise/arritmia/taquicardia/as } \\
\text { sistolia }\end{array}$ & $\begin{array}{l}\text { Hidratação/insulina } \\
\text { antibióticos /suporte } \\
\text { inotrópico/desfibrilação }\end{array}$ & $\begin{array}{l}\text { Óbito } 35 \text { minutos } \\
\text { após PCR }\end{array}$ & \\
\hline
\end{tabular}

AN: acanthosis nigricans, CK- Creatinoquinase, F- Feminino, M- Masculino, MHS- Suscetível à Hipertermia Maligna, IAM- Infarto Agudo Miocárdio, IVCT- Teste de Contratura Muscular In Vitro, PCR- Parada cardiorespiratória, SCAD- deficiência acyl-coA desidrogenase de cadeia curta, TCU - traço cetônico urina. 
Por outro lado, altas doses de insulina poderiam aumentar nível intracelular de cálcio no músculo. Assim pacientes MHS com cetoacidose deveriam ser monitorados quanto a sinais de rabdomiólise durante uso de insulina.

\section{Há risco adicional no uso de drogas ilícitas?}

Há características clínicas semelhantes entre intoxicação por ecstasy, síndrome neuroléptica maligna, síndrome serotoninérgica, choque por calor e HM. O'Leary et al. relatam casos de overdoses com ecstasy (4methylenedioxymethamphethamine: MDMA), que aparecem na literatura entre 1970 e 1980, alguns fatais, expressandose como hiperpirexia, diaforese, desidratação, taquicardia, midríase, ataxia, trismo, rabdomiólise, coagulação intravascular disseminada e falência renal. MDMA estimula receptores de serotonina no SNC (Sistema Nervoso Central). Dantrolene tem sido usado na hipertermia causada pelo MDMA; embora benéfico na crise de HM, seu uso durante intoxicação de ecstasy permanece controverso ${ }^{93,94}$.

Estudo realizado em porcos (seis MHS e seis MHN, expostos a doses cumulativas de MDMA), evidenciou crises de HM em porcos MHS com administração de $8 \mathrm{mg} / \mathrm{kg}$ e aumento moderado do metabolismo nos porcos MHN com doses de $12 \mathrm{mg} / \mathrm{kg}$. A administração de dantrolene durante as crises de HM provocadas por MDMA levou à melhora dos sinais clínicos ${ }^{95}$. 
Foram analisados dois estudos, classificados como relatos de série de casos (nível de evidência 4).

Estudo in vitro, em músculos de pacientes susceptíveis e controles (número não informado), mostrou que em pacientes MHS as contraturas induzidas por cafeína e halotano foram intensificadas tanto por exposição prévia como por exposição posterior a $\mathrm{MDMA}^{96}$.

Klingler W et al. estudaram, por TCHC com halotano e cafeína, dezessete indivíduos com história pessoal ou familiar de intercorrência anestésica (oito MHS, um MHE e oito MHN, confirmados com estudo genético). Expostos a MDMA, os músculos MHS apresentaram contraturas com menores concentrações de halotano/cafeína, enquanto os MHN não tiveram aumento suficiente para satisfazer os critérios de positividade do TCHC. MDMA não age pela liberação de cálcio de vesículas do retículo sarcoplasmático, mas sim pela ativação do receptor de acetilcolina nicotínico (nAChR) na junção neuromuscular. MDMA poderia ser mais tóxico para pessoas com doenças que levem à denervação e aumento de $\mathrm{nAChR}{ }^{97}$.

Além dos riscos inerentes às drogas ilícitas, pacientes susceptíveis à HM devem ser advertidos do perigo adicional de uso desses agentes, em particular MDMA, potencialmente levando mais facilmente a crises semelhantes à HM.

\section{Tenho risco adicional por ser asmático com HM?}

Sinais de intoxicação por teofilina podem se assemelhar à crise de HM, com hipertermia, taquicardia, ocasionalmente 
acidose e rabdomiólise. Seis suínos MHS e seis MHN, anestesiados e entubados para administração crescente de teofilina a cada 20 minutos, apresentaram, instabilidade hemodinâmica e aumento de frequência cardíaca, com posterior morte em todos os animais por fibrilação ventricular após dose de 93,5mg/Kg, sem, contudo, apresentarem sinais de crise de $\mathrm{HM}^{98}$.

Músculos de suínos susceptíveis (MHS) submetidos ao TCHC desenvolveram maior resposta à teofilina (doses de 3 e $5 \mathrm{mmol}-\mathrm{L}$ ) em comparação com animais não susceptíveis (MHN). Entretanto, doses terapêuticas de aminofilina ( $\sim 5 \mathrm{mg} / \mathrm{Kg}-300 \mathrm{mg} / \mathrm{d}$ ) estão correlacionadas a níveis séricos de 5-10mg/L (28 a 55umol/L) ${ }^{99,100}$.

Foi analisado um estudo, classificados como relato de série de casos (nível de evidência 4).

Fiege et al. estudaram resposta de músculo humano à teofilina 3mmol/l em bolus, em 15 pacientes, sendo sete MHS e oito MHN. Músculos dos MHS em geral desenvolveram contraturas enquanto os MHN não apresentaram contraturas com teofilina. Entretanto, no grupo dos MHS, um dos fragmentos de músculo não apresentou contratura após a administração de teofilina e foi observada uma pequena contratura em um dos músculos do grupo dos $\mathrm{MHN}^{101}$.

Não há contraindicação ao uso de antiasmático para MHS, visto que durante o TCHC as contraturas foram induzidas por doses muito mais elevadas do que são normalmente prescritas. 


\section{Há substâncias tóxicas das quais devo me proteger?}

Bifenil policlorados (PCBs) são compostos químicos que dão origem a diversos derivados de elevada toxicidade, persistência ambiental e bioacumulação através da cadeia alimentar ${ }^{102}$.

Ta et al. compararam amostras de retículo sarcoplasmático juncional proveniente de músculos de suínos normais e com mutações para HM, quando expostos ao PCB 95. PCB 95 reduziu a inibição pelo cálcio e pelo magnésio de forma mais intensa no material de porcos mutados em relação aos normais. Adicionalmente, sensibilidade do músculo à cafeína aumentou na presença de PCB em concentração similar à encontrada como contaminante seguro de alimentos e água potável ${ }^{103,104}$.

O fato de que mutações no gene rianodina são expressas não só em fibras musculares, mas também em células dendríticas cerebrais e linfócitos $B$, levanta a possibilidade de que a exposição a PCB e a outros poluentes orgânicos possa produzir um choque toxicológico com maior impacto em indivíduos portadores de mutação. Por outro lado, a exposição a níveis baixos de PCB 95 poderia sensibilizar ainda mais indivíduos MHS para efeitos adversos após uso de agentes anestésicos gerais, despolarizantes musculares ou estresse ambiental geral ${ }^{103}$. Susceptibilidade à HM resulta de interações entre genes e meio ambiente, já que pacientes susceptíveis podem ser expostos a várias anestesias sem desencadear uma crise. Além disso, em uma mesma família, observam-se diferentes intensidades na 
expressão clínica da resposta aos agentes desencadeantes. Exposição humana aos fármacos ou toxinas ambientais, como os PCBs e dioxinas (Agent Orange), que possuem propriedades químicas semelhantes às dos anestésicos voláteis, poderiam teoricamente intensificar uma crise de HM.

Encontramos um relato de caso. Paciente com 45 anos, pai de menina com 12 anos sobrevivente de um episódio de HM, foi diagnosticado como suscetível e apresentava aumento de CK (650UI/L). Ele trabalhava em recarga de extintores de incêndio com bromoclorodifluorometano e, mesmo com a atividade ao ar livre, ocorria à inalação de alguns gases. Houve mal-estar, rigidez e fraqueza no antebraço e na mão durante os 18 meses em que realizou esse trabalho. Sintomas melhoravam durante finais de semana (CK 544UI/L na segunda-feira) e pioravam durante a semana (CK 1.056UI/L no sábado). Pela semelhança estrutural entre o gás e o halotano, o efeito sobre a contratura muscular foi estudado in vitro e verificou-se ser idêntico ao do halotano. Ao mudar de emprego, os sintomas melhoraram. Os autores postulam que este paciente sofreu rabdomiólise de repetição pela exposição ao gás semelhante ao halotano ${ }^{30}$.

Pacientes MHS devem evitar exposição prolongada em locais contaminados bem como evitar residir próximo aos locais onde haja impregnação de PCB. 


\section{Posso usar neurolépticos?}

Síndrome neuroléptica maligna (SNM) é caracterizada por hipertermia, rigidez muscular, alterações de consciência e neurovegetativas, e é uma reação ao uso de neurolépticos ou à retirada abrupta de agentes dopaminérgicos. Etiologia mais aceita é o bloqueio de receptores dopaminérgicos no hipotálamo, de forma que tratamento se baseia no uso de relaxantes musculares (benzodiazepínicos, dantrolene) e na reposição de dopamina (bromocriptina) ${ }^{105}$.

Semelhança dos sinais clínicos levantou a questão de que pacientes com história de SNM poderiam ser susceptíveis à HM, sendo um fator de preocupação quando indicada anestesia geral com agentes desencadeantes ou uso de succinilcolina antes da estimulação elétrica para eletroconvulsioterapia (ECT). Por outro lado, não há relatos de crise de HM com pacientes submetidos a ECT, nem com seus familiares, mesmo sendo administradas doses repetidas de succinilcolina. Embora SMN e HM sejam fisiopatologicamente diferentes pode haver correlação com doenças de base que predisponham às duas síndromes, como sugerido por três relatos de caso ${ }^{106-108}$.

Carole et al. relatam jovem com 21 anos, hospitalizado com sintomas psicóticos e medicado com haloperidol, que apresentou sinais clínicos de SNM e CK aumentado (dezoito vezes acima do normal). Após retirada da droga, hipertermia e rigidez muscular desapareceram. Biópsia muscular diagnosticou Miopatia Central Core. 
Portel et al. descrevem paciente com 36 anos, asmático, hospitalizado com crise aguda de asma, e que necessitou intubação, sendo medicado com corticosteroide, broncodilatadores, bloqueador neuromuscular, sulfato de magnésio e posteriormente halotano. $O$ paciente desenvolveu episódio de $\mathrm{HM}$, com hipertermia de $40^{\circ} \mathrm{C}$ e rabdomiólise, com escore de 45 em 60 na escala de graduação clínica para diagnóstico de HM ("muito provável"). Dantrolene foi administrado e paciente restabeleceu-se. Oito dias após o evento, após injeção de droperidol, o paciente apresentou SNM. Novamente houve boa resposta ao dantrolene. Não houve possibilidade de realizar TCHC para confirmar HM neste caso ${ }^{109}$.

Russell et al. descrevem paciente com variante no gene rianodina que apresentou SNM e rabdomiólise por ecstay ${ }^{110}$.

Foram analisados 11 estudos, classificados como: quatro relatos de casos e sete relatos de séries de casos (nível de evidência 4). Dentre esses 11 estudos, houve sete estudos de pacientes com SNM testados pelo TCHC, um estudo de músculos de pacientes susceptíveis à $\mathrm{HM}$ expostos aos neurolépticos, e um estudo que se enquadrava nos dois grupos anteriores. Além disso, havia um estudo de pacientes com SNM submetidos ao teste com fibras musculares desnudas e outro estudo de mutações do receptor rianodina também de pacientes com SNM. 
Estudos de pacientes com SNM testados pelo TCHC

Para a análise dos relatos de SNM, foi utilizada a classificação do DSM-IV, 2000, que inclui como critérios rigidez muscular, hipertermia, alteração autonômica e mudança do nível consciência, associados ao uso de medicação antipsicótica (frequentemente neuroléptico); para diagnóstico é preciso haver rigidez e hipertermia, além de no mínimo duas outras alterações, incluindo leucocitose e evidência laboratorial de rabdomiólise ${ }^{111}$.

Análise desses trabalhos (Tabela 6) mostra alguns pacientes que não se enquadravam nos critérios diagnósticos de SNM, o que poderia ter explicado resultados negativos no teste de contratura. Outro problema encontrado foi o intervalo entre rabdomiólise e teste de contratura, preconiza-se um intervalo de três a seis meses, para que a necrose não interfira na contratilidade. Entretanto, houve trabalhos que não citaram esse intervalo, ou onde o teste de contratura foi feito em intervalo inferior ao recomendado.

Em particular, Caroff et al. citam que seus resultados não estavam correlacionados com a proximidade dos eventos relacionados aos neurolépticos, nem com rabdomiólise ou níveis elevados de $\mathrm{CK}^{112}$. Assim, dos 35 pacientes estudados, apenas dois se enquadravam nos critérios diagnósticos de SNM e tiveram suas biópsias realizadas após intervalo mínimo de três meses. 
Tabela 6. Pacientes com SNM testados pelo TCHC.

\begin{tabular}{|c|c|c|c|c|c|c|c|}
\hline $\begin{array}{l}\text { Autor } \\
\text { Ano }\end{array}$ & $\begin{array}{l}\text { Idade/ } \\
\text { Sexo }\end{array}$ & Controle & Quadro Clínico/CK & $\begin{array}{l}\text { Critério } \\
\text { SNM (DSM- } \\
\text { IV, 2000) } \\
\end{array}$ & $\begin{array}{l}\text { TCHC, protocolo } \\
\text { Intervalo crise }\end{array}$ & Microscopia & TCHC \\
\hline $\begin{array}{l}\text { Tollefson } \\
1982^{113}\end{array}$ & $41 \mathrm{a} / \mathrm{M}$ & - & $\begin{array}{l}\text { Hipertermia/diaforese/rigi } \\
\text { dez/taquipneia } \\
\text { mutismo/acinesia/taquica } \\
\text { rdia instabilidade PA }\end{array}$ & Sim & Halotano/cafeína & $\begin{array}{l}\text { Atrofia tipos I e II } \\
\text { targets: } \\
\text { atrofia } \\
\text { neurogênica }\end{array}$ & MHN \\
\hline $\begin{array}{l}\text { Scarlett } \\
1983^{114}\end{array}$ & $50 a / F$ & - & $\begin{array}{l}\text { Hipertermia/rigidez/sialor } \\
\text { reia/mutismo/tremor } \\
\text { taquicardia/CK } 2.438 \mathrm{UI} / \mathrm{L}\end{array}$ & Sim & $\begin{array}{l}\text { Halotano/cafeína/clo } \\
\text { reto } \\
\text { potássio/succinilcoli } \\
\text { na/ }\end{array}$ & $\begin{array}{l}\text { Variação calibre, } \\
\text { condensações } \\
\text { sarcoplasma, } \uparrow \\
\text { lipídico } \\
\text { mitocondrial, }\end{array}$ & MHN \\
\hline \begin{tabular}{|l} 
Denborough \\
$1984^{108}$
\end{tabular} & $31 \mathrm{a} / \mathrm{M}$ & - & $\begin{array}{l}\text { Hipertermia/Náusea/sono } \\
\text { lência/convulsão } \\
\text { mioglobinúria/CK } \\
5.3000 U I / L\end{array}$ & Não & $\begin{array}{l}\text { Halotano/cafeína } \\
\text { Intervalo: } 2 \text { meses }\end{array}$ & - & MHS \\
\hline $\begin{array}{l}\text { Merry } \\
1988^{116}\end{array}$ & $14 a / M$ & - & $\begin{array}{l}\text { Hipertermia/rigidez/trem } \\
\text { or/disartria/diaforese/disf } \\
\text { agia CK1.500UI/L } \\
\text { acinesia/PA } \\
\text { instável/sialorréia/taquica } \\
\text { rdia }\end{array}$ & Sim & Halotano/cafeína & - & MHN \\
\hline $\begin{array}{l}\text { Caroff } \\
1987^{112}\end{array}$ & $\begin{array}{l}63 a / M \\
30 a / M \\
22 a / F \\
52 a / M \\
26 a / M \\
36 a / F \\
50 a / M\end{array}$ & \begin{tabular}{|l|}
$12: 6 \mathrm{SD}$ \\
$\mathrm{HM}$ \\
$2 \mathrm{M} / 4 \mathrm{~F}$ \\
média \\
$29 a$ \\
6 \\
controles \\
cirúrgicos \\
$1 \mathrm{M} / 5 \mathrm{~F}$ \\
média \\
$41 \mathrm{a}$ \\
\end{tabular} & $\begin{array}{l}\text { Hipertermia/rigidez/ } \\
\text { estupor/dispneia/delirium } \\
\text { /mutismo } \\
\text { taquicardia/CK 381- } \\
\text { 100.000UI/L }\end{array}$ & Sim & \begin{tabular}{|l|} 
Flufenazina \\
Halotano \\
Intervalo: $8-60$ dias \\
pós normalização \\
CK
\end{tabular} & - & $\begin{array}{l}\text { MHS } \\
\text { MHN } \\
\text { MHS } \\
\text { MHS } \\
\text { MHS } \\
\text { MHS } \\
\text { MHN }\end{array}$ \\
\hline $\begin{array}{l}\text { Krivosic } \\
1987^{117}\end{array}$ & $\begin{array}{l}37 a / F \\
40 a / F \\
54 a / M \\
73 a / M \\
40 a / M \\
58 a / F \\
\end{array}$ & - & $\begin{array}{l}\text { Hipertermia/rigidez/acine } \\
\text { sia/ estupor/\consciência } \\
\text { disfunções autonômicas } \\
\text { rabdomiólise/IRA } \\
\text { CK } 10.000-56.000 \mathrm{U} / \mathrm{L}\end{array}$ & $\begin{array}{l}\text { Sim } \\
\text { Sim } \\
\text { Sim } \\
\text { Não } \\
\text { Sim } \\
\text { Não }\end{array}$ & $\begin{array}{l}\text { Europeu } \\
\text { Intervalo mínimo } \\
48 \text { horas após } \\
\text { suspensão } \\
\text { dantrolene }\end{array}$ & - & $\begin{array}{l}\text { MHN } \\
\text { MHEC } \\
\text { MHN } \\
\text { MHN } \\
\text { MHN } \\
\text { MHN } \\
\end{array}$ \\
\hline \begin{tabular}{|l} 
Adnet \\
$1989^{118}$
\end{tabular} & $\begin{array}{l}36 a / F \\
60 a / F \\
28 a / M \\
35 a / F \\
39 a / F \\
48 a / M \\
50 a / F \\
60 a / M\end{array}$ & $\begin{array}{l}\text { 20: } 10 \\
\text { com SD } \\
\text { HM } \\
\text { (média } \\
29 a) \text { e } 10 \\
\text { ortopédic } \\
\text { os } \\
\text { (6F/4M, } \\
\text { média } \\
41 a)\end{array}$ & $\begin{array}{l}\text { (Critério Levenson) } \\
\text { Hipertermia } \\
\text { rigidez/acinesia } \\
\text { taquicardia diaforese } \\
\downarrow \text { consciência rabdomiólise } \\
\text { CK }>1.000 \cup I / L\end{array}$ & Sim & $\begin{array}{l}\text { Europeu }+ \\
\text { clorpromazina } \\
\text { Intervalo: } \\
\text { 2-3 semanas pós- } \\
\text { SNM } \\
48 \text { horas após } \\
\text { suspensão } \\
\text { dantrolene }\end{array}$ & - & MHN \\
\hline
\end{tabular}


Tabela 6 (cont.). Pacientes com SNM testados pelo TCHC.

\begin{tabular}{|c|c|c|c|c|c|c|c|}
\hline $\begin{array}{l}\text { Autor } \\
\text { Ano }\end{array}$ & \begin{tabular}{|l|} 
Idade/ \\
Sexo
\end{tabular} & Controle & Quadro Clínico/CK & $\begin{array}{l}\text { Critério } \\
\text { SNM (DSM- } \\
\text { IV, 2000) }\end{array}$ & $\begin{array}{l}\text { TCHC, protocolo } \\
\text { Intervalo crise }\end{array}$ & Microscopia & TCHC \\
\hline $\begin{array}{l}\text { Silva } \\
2000^{119}\end{array}$ & $\begin{array}{l}23 a / F \\
23 a / M \\
43 a / M\end{array}$ & - & $\begin{array}{l}\text { Hipertermia/ } \downarrow \text { consciência } \\
\text { convulsões/rigidez/rabdo } \\
\text { miólise síndrome } \\
\text { compartimental/IRA } \\
\text { CK 324-7.550UI/L }\end{array}$ & $\begin{array}{l}\text { Sim } \\
\text { Sim } \\
\text { Não }\end{array}$ & $\begin{array}{l}\text { Europeu } \\
\text { Intervalo } 6 \text { meses - } \\
2 \text { anos pós SNM }\end{array}$ & $\begin{array}{l}\text { Variação } \\
\text { calibre/atrofia/ } \\
\text { hipertrofia fibras } \\
\text { fendidas/necrose/ } \uparrow \\
\text { endomisial/ } \\
\text { agrupamento } \\
\text { fibras I/ falhas nas } \\
\text { reações oxidativas } \\
/ \uparrow \text { tríades/ } / \text { lípides } \\
\text { alteração cristas } \\
\text { mitocondriais }\end{array}$ & $\begin{array}{l}\text { MHEC } \\
\text { MHEh } \\
\text { MHEh }\end{array}$ \\
\hline $\begin{array}{l}\text { Arakil } \\
1988^{120}\end{array}$ & $\begin{array}{l}41 a / F \\
14 a / F \\
21 a / F \\
60 a / M \\
40 a / F \\
21 a / M \\
36 a / F \\
63 a / M\end{array}$ & \begin{tabular}{|l|} 
Controles \\
cirúrgicos \\
(idade 18 \\
a 69a)
\end{tabular} & $\begin{array}{l}\text { Hipertermia/rabdomiólise } \\
\text { CK } 1.084-111.500 \mathrm{UI} / \mathrm{L}\end{array}$ & Não & $\begin{array}{l}\text { Cafeína } \\
\text { Intervalo } \\
4-90 \text { dias }\end{array}$ & $\begin{array}{l}\text { Atrofia fibras tipo } \\
\text { 2B e } 2 \mathrm{C} / \\
\text { internalização } \\
\text { nuclear /necrose/ } \\
\text { fagocitose / fibra } \\
\text { fendida }\end{array}$ & SNM \\
\hline
\end{tabular}

CK- Creatinoquinase, DSM-IV, 2000- Manual Diagnóstico e Estatístico de Transtornos Mentais, F- Feminino, IRA- Insuficiência Renal Aguda, M- Masculino, MHEc- Suscetível à Hipertermia Maligna após resposta com Cafeína, MHEh- suscetível à Hipertermia Maligna após resposta com Halotano,MHS- Suscetível à Hipertermia Maligna, MHN- Hipertermia Maligna Negativo, PA- Pressão Arterial, SD- Suposição Diagnóstica, SNM- Síndrome Neuroléptica Maligna, TCHC- Teste de Contratura Halotano Cafeína.

Músculos de pacientes susceptíveis à HM expostos aos neurolépticos

Presença de dois estudos de séries de casos (nível de evidência 4), com resultados conflitantes, sendo que o estudo que mostrou resposta do músculo MHS ao neuroléptico não empregou o protocolo convencional para o TCHC norte-americano.

Tabela 7. Músculos de pacientes susceptíveis à HM expostos aos neurolépticos.

\begin{tabular}{|l|l|l|l|l|}
\hline Autor/Ano & MHS & Controles & Neurolépticos & Resposta Neurolépticos \\
\hline Caroff $1987^{112}$ & $\begin{array}{l}\text { 6: } 2 \mathrm{M} \mathrm{e} \mathrm{4F} \\
(29+-3 a)\end{array}$ & $\begin{array}{l}\text { 6: } 1 \mathrm{M} \text { e 5F } \\
(41+-6 a)\end{array}$ & Flufenazina & $\begin{array}{l}\text { Sem diferenças estatísticas } \\
\text { significantes entre os grupos }\end{array}$ \\
\hline $\begin{array}{l}\text { Fletcher } \\
1989^{121}\end{array}$ & 12 & 5 & Haloperidol & $\begin{array}{l}\text { Aumentou as contraturas } \\
\text { induzidas por halotano } \\
\text { seguido de succinilcolina, em } \\
\text { MHS }\end{array}$ \\
\hline
\end{tabular}


Sato et al. pesquisaram mutação do gene da RyR1 em onze pacientes psiquiátricos suspeitos de morte por SNM e que apresentaram aumento de temperatura que se manteve no pós morte. Encontraram-se dois casos com mutações distintas no RYR1, a R4645Q (já descrita em japoneses) e a mutação $A 612 T^{122}$. Além dos autores citarem que não havia dados para enquadrar os pacientes nos critérios diagnósticos de SNM, essas mutações ainda não estavam na lista de mutações patogênicas para HM.

Dados encontrados não permitem definir com precisão a associação entre SNM e HM. Enquanto isso é recomendável que pacientes MHS em utilização de neurolépticos sejam monitorados quanto a sinais de hipertermia e aumento de CK. Por outro lado, sugere-se monitorização cuidadosa em procedimentos onde pacientes com história de SNM que utilizem os agentes desencadeantes de HM.

\section{Posso fazer tratamento odontológico? Posso usar anestesia local?}

Apesar da anestesia local ser muito utilizada, raramente podem ocorrer reações alérgicas causadas por anestésicos locais. Principais sinais são: eritema local, urticária, broncoespasmo, hipotensão e colapso cardiovascular. Além disso, efeitos tóxicos podem ser causados por dose excessiva ou pela injeção inadvertida via intravascular ou intratecal. Os sintomas são variáveis: tonturas, perturbações visuais, zumbido, dormência em língua e lábios, contrações 
musculares, tremores, convulsões, e até mesmo depressão respiratória, com arritmias e hipotensão severa ${ }^{123}$.

Frequentemente pacientes susceptíveis à $\mathrm{HM}$ e seus dentistas questionam sobre a segurança de anestesia para procedimentos dentários. Murray et al. afirmam que não existem provas sólidas contra uso de anestésicos e vasoconstritores locais, e esses agentes podem ser utilizados como indicado em prática clínica para pacientes susceptíveis à HM. Assim, seria possível realização de anestesias locais durante tratamento dentário sem riscos, desde que não haja necessidade de anestesia geral utilizando anestésicos halogenados e succinilcolina, que desencadeiam crise de $\mathrm{HM}^{124,125}$.

Qualquer dos anestésicos locais comumente usados são seguros, assim lidocaína, mepivacaína, articaína e bupivacaína são adequados. Quando possível, evitar uso de prilocaína, pois há possibilidade de que em altas doses induza alterações da metemoglobina, causando cianose, um dos sinais que acompanham a crise de $H M$ e, assim, possibilitando confundir o diagnóstico ${ }^{126}$.

Todas as crises de HM durante tratamento odontológico estavam associadas à anestesia geral com agentes desencadeantes halogenados e/ou succinilcolina. Não foram encontrados artigos em que crise de HM tenha sido ocasionada por anestesia local durante cirurgia odontológica127,128.

Nagasawa em estudo experimental com animais avaliou se o éster metílico do ácido 4-hidroxibenzóico, conservante 
na solução de lidocaína, poderia provocar crise de HM em paciente susceptível. O éster metílico 4-hidroxibenzóico acelerou a liberação de cálcio do retículo sarcoplasmático de maneira dose-dependente e a curva de dose-resposta foi deslocada para esquerda em concentrações acima de 30 microM. Essa concentração plasmática de lidocaína é tóxica e induziria convulsão, de forma que lidocaina só teria potencial de provocar crise de HM em pacientes susceptíveis se acidentalmente fosse administrada por via venosa ${ }^{129}$.

Foram analisados seis estudos sobre uso dos anestésicos locais (amidas e aminas) e adrenalina em MHS, classificados como: cinco relatos de caso e um relato de série de casos (nível de evidência 4).

Paciente de 16 anos de idade, com história prévia de HM em anestesia geral, foi anestesiado outras três vezes para biópsia do músculo sob anestesia peridural com procaína a $2 \%$ e duas cirurgias para reparação de tornozelo. Na primeira cirurgia para correção do tornozelo foi utilizada procaína a $2 \%$ para a anestesia peridural, e sintomas semelhantes à HM foram observados, dez minutos após a deflação do garrote anexado na coxa com uma pressão de $500 \mathrm{mmHg}$, que fora utilizado por uma hora. Foi tratado com dantrolene e bicarbonato de sódio, para correção de acidose metabólica possivelmente causada pelo garrote. Na segunda cirurgia para reparação do descolamento do tendão e retirada de pinos do tornozelo direito, foi feita anestesia peridural com mepivacaína, sem torniquete e paciente não apresentou sinais de $\mathrm{HM}^{130}$. 
Homem de 62 anos, submetido à ressecção transuretral de próstata sob raquianestesia com $12 \mathrm{mg}$ de tetracaína, não recebeu qualquer outra medicação desencadeadora de HM. Uma hora depois, desenvolveu taquipneia e rigidez muscular. Paciente foi medicado com diazepam, midazolam e propofol. Foi realizada RCP e transferência para outro hospital em coma grave, rigidez muscular generalizada, temperatura oral de $42,2^{\circ} \mathrm{C}$, acidose metabólica, leucocitose, hiperuricemia e elevação de lactato desidrogenase e creatinina fosfoquinase (pico 26.000UI/l após 48h). Dantrolene reverteu crise. Culturas de sangue, secreção traqueal, urina e líquido cefalorraquidiano foram negativas. Não foi realizado TCHC para investigar susceptibilidade à $\mathrm{HM}^{131}$.

Paciente com 36 anos, em cirurgia eletiva para retirada de cálculo uretral esquerdo, sob anestesia espinal com tetracaína $10 \mathrm{mg}$ e posteriormente com tetracaína $8 \mathrm{mg}$, por falta de resultados na primeira administração, apresentou crises convulsivas atribuídas à toxicidade do anestésico local.

Kemp et al. descreve paciente com 53 anos, em uso de verapamil $80 \mathrm{mg} / \mathrm{dia}$, com história familiar de HM, submetido a apendicectomia com bupivacaína $25 \mathrm{mg}$ via subaracnoide. Paciente apresentou tremores, hipertermia, hipotensão, taquicardia, hipocalcemia, acidose metabólica, e elevação de aspartate aminotransferase, gama glutamil transferase e CK. Foi administrado dantrolene e paciente sobreviveu, mas não foi possível realizar a biópsia muscular para confirmar a susceptibilidade à $\mathrm{HM}^{132}$. 
Paciente com 51 anos foi submetido a três cirurgias urológicas com raquianestesia, desencadeando hipertermia e tremores, e levando a suspeita de crise de HM. Paciente recusou o TCHC, mas biopsia muscular em suas filhas detectou miopatia.

Estudo retrospectivo com 307 indivíduos com história pessoal ou familiar de HM, cadastrados na MHAUS, foi realizado com base em entrevistas sobre tratamento odontológico. Trinta e seis indivíduos (12\%) relataram reações adversas tais como febre, cãibras musculares, disritmia, dor de cabeça, espasmos musculares, perda de consciência, fraqueza, dores musculares, mal-estar e rigidez de face, pescoço e braço. Um dos entrevistados relatou sintomas suspeitos de HM, como febre e dores musculares, após a administração de anestésicos locais tipo amida, porém os sintomas desapareceram sem a necessidade de terapia indicada para HM. Cinquenta e seis (18\%) relataram dificuldade em receber atendimento após a identificação como susceptíveis à HM, dentre os quais 27 indivíduos foram recusados para tratamento odontológico e/ou se submeteram a procedimentos cirúrgicos sem anestesia local ${ }^{133}$.

Não existem contraindicações ao uso de anestesias locais em pacientes susceptíveis à HM, embora seja relevante que todos os profissionais que utilizam esses agentes tenham conhecimento da fisiopatologia de HM. Relatos de reações aos anestésicos locais podem ser explicados por outras razões, como efeito do garrote, 
administração acidental intravascular/intratecal e miopatias subjacentes, que são fatores de risco a serem lembrados em pacientes susceptíveis à HM.

\section{4. É seguro o uso de fórmulas contendo heparina?}

4-cloro-m-cresol ( $4 \mathrm{CmC}$ ) induz contraturas em músculo esquelético de indivíduos susceptíveis à hipertermia maligna. Sabe-se que $4 \mathrm{CmC}$ é preservativo de vários medicamentos como insulina, heparina e succinilcolina. Estudos com animais demonstraram que $4 \mathrm{CmC}$ pode desencadear crise de $\mathrm{HM}^{87}$.

4-cloro-m-cresol pode causar crise de HM em suínos sensíveis, mas somente quando concentrações séricas são muito superiores às administradas em seres humanos. Baixa concentração de $4 \mathrm{CmC}$ (50micromol) é suficiente para aumentar cálcio sarcoplasmático e em estudos in vitro causa contraturas, porém esta mesma dose administrada em bolus in vivo $(0,57 \mathrm{mg} / \mathrm{kg})$ não tem capacidade de desenvolver crise, pela rápida diminuição de níveis plasmáticos ${ }^{134}$.

Foram analisados quatro estudos, classificados como: um relato de caso e três relatos de série de casos (nível de evidência 4).

Paciente, 54 anos, masculino, com história familiar de HM, foi submetido à cirurgia eletiva de revascularização do miocárdio com circulação extracorpórea hipotérmica, sob administração de heparina com dose não informada, sem utilização de agentes desencadeantes de HM. Apresentou sinais de HM no pós-operatório (rigidez, hipertermia $38,3^{\circ} \mathrm{C}$, 
acidose metabólica) e foi tratado com dantrolene com sucesso. Recusou-se a realizar TCHC. Paciente não usava outras drogas cardiovasculares nem neurolépticos, e crise foi atribuída ao reaquecimento após a hipotermia ${ }^{135}$.

Estudo multicêntrico em seis centros europeus de HM, realizados com 202 pacientes submetidos ao TCHC, tiveram 4CmC adicionado ao banho de halotano e cafeína com resultados de contraturas significativamente maiores em fragmentos de músculos de MHS ou HME, sem contratura em músculo de pacientes não susceptíveis à HM. Outro estudo multicêntrico foi realizado com 352 pacientes de 11 laboratórios europeus de HM, verificando a contratura in vitro com bolus de 4-cloro-m-cresol, aumentando sensibilidade $(96,1 \%)$ e especificidade $(99,0 \%)$ do teste de contratura in vitro ${ }^{136,137 .}$

Anetseder et al. realizaram estudos in vitro com fragmentos musculares de 16 MHS e 22 MHN, acrescentando $4 \mathrm{CmC}$ ao teste de contratura. Foram observadas contraturas significativas em músculos de MHS comparados com MHN. Porém, estudo in vivo, realizado com 12 pacientes que receberam liquemine $500 \mathrm{UI} / \mathrm{Kg}$ antes de serem submetidos à circulação extracorpórea, verificou através de técnica de cromatografia líquida que concentrações séricas de $4 \mathrm{CmC}$ eram inferiores a $1 / 15$ da concentração utilizada in vitro ${ }^{138}$.

Fórmulas de heparina induzem contratura in vitro em músculo de susceptíveis à HM, porém doses muito maiores seriam necessárias para induzir crises in vivo. Não há risco 
para pacientes que recebem concentrações terapêuticas de heparina.

\section{CONCLUSÃO}

Revisão bibliográfica sobre repercussões da susceptibilidade à HM no dia a dia do paciente detectou 14 pontos de interesse que foram analisados e permitiram elaboração das recomendações para manual de orientações disponibilizado via online.

Recomendações tem impacto no uso de medicamentos e drogas, atividade esportiva e laboral, atendimento dentário, aconselhamento pré-natal e manejo de doenças associadas pré-existentes.

\section{AGRADECIMENTOS}

Conselho Nacional de Desenvolvimento Científico e Tecnológico (CNPQ), Coordenação de Aperfeiçoamento de Pessoal de Nível Superior-Brasil (CAPES), Código de Financiamento 001, Fundação de Amparo à Pesquisa do Estado de São Paulo (FAPESP), 1996/2222-3 e 1996/087435.

Este manuscrito está vinculado à tese de mestrado intitulada Pacientes com Hipertermia Maligna: Estudo do Impacto da Doença e Criação Preliminar de Manual de Orientação.

\section{REFERÊNCIAS}

1.Rosenberg $H$, Sambuughin N, Riazi S, Dirksen R. Malignant Hyperthermia Susceptibility. In: Adam MP, Ardinger HH, Pagon RA, 
Wallace SE, Bean LJH, Stephens K, et al (eds.). GeneReviews ${ }^{\circledR}$. Seattle: University of Washington; 2020. https://pubmed.ncbi.nlm.nih.gov/20301325/

2.Moher D, Cook DJ, Eastwood S, Olkin I, Rennie D, Stroup DF. Improving the quality of reports of meta-analyses of randomised controlled trials: the QUOROM statement. Quality of Reporting of Metaanalyses. Lancet 1999;27:1896-900. https://doi.org/10.1016/s01406736(99)04149-5

3. Howick J, Chalmers I, Glasziou P, Greenhalgh T, Heneghan C, Liberati $A$, et al. The Oxford Levels of Evidence 2 (endereço na internet). Oxford Centre for Evidence-Based Medicine acessado em 2021). Disponível em: https://www.cebm.ox.ac.uk/resources/levels-ofevidence/ocebm-levels-of-evidence

4.Centro de Estudos, Diagnóstico e Investigação de Hipertermia Maligna (endereço na internet). São Paulo: Unifesp. www.cedhima.unifesp.br

5.Rodrigues G, Amaral JLG, Silva HCA. Hipertermia Maligna Manual de Orientação. Registro Câmara Brasileira do Livro no DA-2020-004537. https://cedhima.unifesp.br/images/HMManual.pdf

6. Rodrigues G. Pacientes com Hipertermia Maligna: Estudo do Impacto da Doença e Elaboração Preliminar do Manual de Orientação (Tese). São Paulo: Universidade Federal de São Paulo; 2010. http://repositorio.unifesp.br/handle/11600/19356.

7.Rodrigues G. Aplicabilidade de manual de orientação via internet para doença rara hipertermia maligna (Tese). São Paulo: Universidade Federal de São Paulo; 2021.

8. Moreira MF, Nobrega MML, Silva MIT. Comunicação escrita: contribuição para a elaboração de material educativo em saúde. Rev Bras Enferm 2003;56:184.

https://doi.org/10.1590/S0034-71672003000200015

9.Gerdes C, Richter A, Annies R, Löscher W. Increase of serotonin in plasma during onset of halothane-induced malignant hyperthermia in pigs. Eur J Pharmacol 1992;10:91-4. https://doi.org/10.1016/00142999(92)90016-W

10.Wappler F, Fiege M, Schulte am Esch J. Pathophysiological role of the serotonin system in malignant hyperthermia. $\mathrm{Br}$ J Anaesth 2001;87:783-7. https://doi.org/10.1093/bja/87.5.794

11.Ooms L, Awouters F, Degryse A, Jageneau T. Serotonin and S2 antagonists in veterinary medicine. In: Ruckebusch $\mathrm{Y}$, Toutain $\mathrm{P}-\mathrm{L}$, Koritz GD (eds). Veternary Pharmacolog and Toxicology. Boston: MTP Press; 1983; p263-81.

https://link.springer.com/chapter/10.1007/978-94-009-6604-8 28

12.Stanley TH, Port JD, van der Maantin J, Kimball J. Treatment of stress hyperthermia in elk with ketanserin, a serotonin receptor blocker. Vet Surg 1986;15:214-7.

https://doi.org/10.1111/j.1532950X.1986.tb00208.x

13.Loscher W, Witte U, Fredow G, Ganter M, Bick K. Pharmacodynamic effects of serotonin (5-HT) receptor ligands in pigs: stimulation of 5HT 2 receptors induces malignant hyperthermia. Naunyn- 
Schmiedebergs

https://doi.org/10.1007/BF00171727

14. Wappler F, Roewer N, Kochling A, Scholz J, Loscher W, Steinfath M, et al. Effects of the Serotonin ${ }^{2}$ Receptor Agonist DOI on Skeletal Muscle Specimens from Malignant Hyperthermia-susceptible Patients. Anesthesiology 1996;84:1280-7.

https://doi.org/10.1097/00000542-199606000-00002

15.Gener B, Burns JM, Griffin S, Boyer EW. Administration of ondansetron is associated with lethal outcome. Pediatrics 2010;125:1514-7. https://doi.org/10.1542/peds.2009-2795

16.Wappler F, Scholz J, von Richthofen V, Fiege M, Köchling A, Lambrecht $W$, et al. Attenuation of serotonin-induced contractures in skeletal muscle from malignant hyperthermia-susceptible patients with dantrolene. Acta Anaesthesiol Scand 1997;41:1312-8. https://doi.org/10.1111/j.1399-6576.1997.tb04650.x

17. Wappler F, Scholz J, Oppermann S, von Richthofen V, Steinfath M, Schulte am Esch J. Ritanserin attenuates the in vitro effects of the 5HT2 receptor agonist DOI on skeletal muscles from malignant hyperthermia-susceptible patients. J Clin Anesth 1997;9:306-11. https://doi.org/10.1016/s0952-8180(97)00008-1

18. Wappler F, Scholz J, Fiege M, Richter A, Steinfath M, Weisshorn R, et al. 5-HT2 receptor antagonist-mediated inhibition of halothaneinduced contractures in skeletal muscle specimens from malignant hyperthermia susceptible patients. Naunyn Schmiedebergs Arch Pharmacol 1999;360:376-81.

https://doi.org/10.1007/s002109900062

19.Chu A, Wadhwa R. Selective Serotonin Reuptake Inhibitors. In: StatPearls. Treasure Island: StatPearls Publishing; 2020. https://www.ncbi.nlm.nih.gov/books/NBK554406/

20.Johannsen S, Roewer N, Schuster F. Ondansetron-induced muscular contractures in malignant hyperthermia-susceptible individuals. Anesth Analg 2012;115:925-8.

https://doi.org/10.1213/ANE.0b013e31825d3749

21.Alós JI. Quinolonas. Enferm Infecc Microbiol Clin 2003:21:261-8. https://doi.org/10.1016/s0213-005x(03)72932-2

22. Metterlein T, Schuster F, Tadda L, Hager M, Muldoon S, Capacchione $\mathrm{J}$, et al. Fluoroquinolones influence the intracellular calcium handling in individuals susceptible to malignant hyperthermia. Muscle Nerve 2011;44:208-12. https://doi.org/10.1002/mus.22021

23.Guis S, Bendahan D, Kozak-Ribbens G, Mattei JP, Le Fur Y, ConfortGouny $S$, et al. Investigation of fluoroquinolone-induced myalgia using (31)P magnetic resonance spectroscopy and in vitro contracture tests. Arthritis Rheum 2002;46:774-8. https://doi.org/10.1002/art.10094

24.Denborough MA. Heat stroke and malignant hyperpyrexia. Med J Aust $\quad 1982 ; i: 204-5 . \quad$ https://doi.org/10.5694/j.13265377.1982.tb132267.x

25. Figarella-Branger D, Kozak-Ribbens G, Rodet L, Aubert M, Borsarelli J, Cozzone PJ, et al. Pathological findings in 165 patients explored for 
malignant hyperthermia susceptibility. Neuromus Dis 1993;3:553-6. https://doi.org/10.1016/0960-8966(93)90114-Y

26. Bendahan D, Kozak-Ribbens G, Confort-Gouny S, Ghattas B, Figarella-Branger $D$, Aubert $M$, et al. A Noninvasive Investigation of Muscle Energetics Supports Similarities Between Exertional Heat Stroke and Malignant Hyperthermia. Anest Analg 2001;93:683-9. https://doi.org/10.1097/00000539-200109000-00030

27.Wappler F, Fiege M, Steinfath M, Agarwal K, Scholz J, Singh S, et al. Evidence for susceptibility to malignant hyperthermia in patients with exercise-induced rhabdomyolysis. Anesthesiology 2001;94:95100. https://doi.org/10.1097/00000542-200101000-00019

28. Davis $M$, Brown $R$, Dickson A, Horton $H$, James $D$, Laing $N$, et al. Malignant hyperthermia associated with exercise-induced rhabdomyolysis or congenital abnormalities and a novel RYR1 mutation in New Zealand and Australian pedigrees. Br J Anaesth 2002;88:50815. https://doi.org/10.1093/bja/88.4.508

29.Kozak-Ribbens G, Rodet L, Petrognani R. Hiperthermie d'effort (HE); résultats des explorations de 55 patients. In: Novelli GP, Tegazzin V (eds.). Workshop in Anaesthesia and Pharmacogenic Disease: malignant hyperthermia. Minerva Anestesiol 1994;60(suppl 3):177-81.

30.Denborough MA. Malignant hyperthermia. The Lancet 1998;352:3. https://doi.org/10.1016/S0140-6736(98)03078-5

31. Hackl W, Winkler M, Mauritz W, Sporn P, Steinbereithner K. Muscle biopsy for diagnosis of malignant hyperthermia susceptibility in two patients with severe exercise-induced myolysis. $\mathrm{Br}]$ Anaesth 1991;66:138-40. https://doi.org/10.1093/bja/66.1.138

32. Hopkins $P$ M, Ellis F R, Halsall $P$ J. Evidence for related myopathies in exertional heat stroke and malignant

hyperthermia. Lancet 1991;338:1491-2.

https://doi.org/10.1016/0140-6736(91)92304-k

33. Watson DB, Gray GW, Doucet J]. Exercise rhabdomyolysis in military aircrew: two cases and a review of aeromedical disposition. Aviat Space Environm Med 2000;71:1137-41.

https://pubmed.ncbi.nlm.nih.gov/11086669/

34.Pamukcoglu T. Sudden death due to malignant hyperthermia. Am J Forensic Med Pathol 1988;9:161-2.

https://doi.org/10.1097/00000433-198806000-00015

35. Ryan JF, Tedeschi LG. Sudden unexplained death in a patient with a family history of malignant hyperthermia. J Clin Anesth 1997;9;668. https://doi.org/10.1016/S0952-8180(96)00207-3

36.Köchling A, Wappler F, Winkler G, Esch J. Rhabdomyolysis following Severe Physical Exercise in a Patient with Predisposition to Malignant Hyperthermia. Anaesthes Inten Care 1998;26:315-8.

https://doi.org/10.1177/0310057X9802600317

37.Tobin JR, Jason DR, Challa VR, Nelson TE, Sambuughin N. Malignant Hyperthermia and Apparent Heat Stroke. JAMA 2001;286:168-9. https://doi.org/10.1001/jama.286.2.168 
38. Campbell IT, Ellis FR, Evans RT, Mortimer MG. Studies of body temperatures, blood lactate, cortisol and free fatty acid levels during exercise in human subjects susceptible to malignant hyperpyrexia. Acta Anaesthesiol Scand 1983;27:349-55.

https://doi.org/10.1111/j.1399-6576.1983.tb01966.x

39. Hayward JS, Eckerson JD, Dawson BT. Effect of mesomorphy on hyperthermia during exercise in a warm, humid environment. Am J Phys Anthrop 1986;70:11-7.

https://doi.org/10.1002/ajpa.1330700104

40.Porter AMW. Collapse from exertional heat ilness: Implicationss and subsequente decisisons. Milit Med 2003;168:76-81. https://pubmed.ncbi.nlm.nih.gov/12546251/

41.Jacquot C, Stieglitz. Conduite à tenir devant um sujet susceptible de présenter une hyperthermie maligne em cãs d'anesthésie et dans la vie quotidienne Anaesthesia and counselling of malignant hyperthermia susceptible patients. Ann Fr Anesth Réanim 1989;8:417-26. https://doi.org/10.1016/S0750-7658(89)80008-5

42.London SF, Gross KF, Ringel SP. Cholesterol-lowering agent myopathy (CLAM). Neurology 1991;41:1159-60. https://doi.org/10.1212/wnl.41.7.1159

43. Meriggioli MN, Barboi AC, Rowin J, Cochran EJ. HMG-CoA Reductase Inhibitor Myopathy: Clinical, Electrophysiological, and Pathologic Data in Five Patients. J Clin Neuromuscul Dis 2001;2:12934. https://pubmed.ncbi.nlm.nih.gov/19078619/

44.Sharobeem KM, Madden BP, Millner R, Rolfe LM, Seymour CA, Parker J. Acute renal failure after cardiopulmonary bypass: a possible association with drugs of the fibrate group. J Cardiovasc Pharmacol Ther 2000;5:33-9. https://doi.org/10.1177/107424840000500105 45.Wilhelmi M, Winterhalter M, Fischer S, Walles T, Zuk J, Strüber M, et al. Massive postoperative rhabdomyolysis following combined CABG/abdominal aortic replacement: a possible association with HMGCoA reductase inhibitors. Cardiovasc Drugs Ther 2002;16:471-5. https://doi.org/10.1023/a:1022198705168

46.Guis S, Mattéi JP, Lioté F. Drug-induced and toxic myopathies. Best Pract Res Clin Rheumatol 2003;17:877-907.

https://doi.org/10.1016/j.berh.2003.11.002

47.Krivosic-Horber R, Dépret T, Wagner JM, Maurage CA. Malignant hyperthermia susceptibility revealed by increased serum creatine kinase concentrations during statin treatment. Eur J Anaesthesiol 2004;21:572-4. https://doi.org/10.1017/s0265021504227120

48.Guis S, Figarella-Branger D, Mattei JP, Nicoli F, Le Fur Y, KozakRibbens $\mathrm{G}$, et al. In vivo and in vitro characterization of skeletal muscle metabolism in patients with statin-induced adverse effects. Arthritis Rheum 2006;15;55:551-7. https://doi.org/10.1002/art.22100

49.Katiriji B, Al Jaberi MM. Creatine kinase revisited. J Clin Neuromuscul Dis 2001;2:158-64. https://doi.org/10.1097/00131402200103000-00008

50.Vladutiu GD, Isackson PJ, Kaufman K, Harley JB, Cobb B, Christopher-Stine $\mathrm{L}$, et al. Genetic risk for malignant hyperthermia in 
non-anesthesia-induced myopathies. Mol Genet Metab 2011;104:16773. https://doi.org/10.1016/j.ymgme.2011.07.001

51.Isackson PJ, Wang J, Zia M, Spurgeon P, Levesque A, Bard J, et al. RYR1 and CACNA1S genetic variants identified with statin-associated muscle symptoms. Pharmacogenomics 2018;19:1235-49. https://doi.org/10.2217/pgs-2018-0106

52. Rosenberg H, Grant M. Ascending tonic-clonic syndrome secondary to intrathecal Omnipaque. J Clin Anesth 2004;16:299-300. https://doi.org/10.1016/j.jclinane.2004.03.002

53.Ong RO, Rosenberg $\mathrm{H}$. Malignant hyperthermia-like syndrome associated with metrizamide myelography. Anesth Analg 1989;68:795-7. https://pubmed.ncbi.nlm.nih.gov/2735545/

54. Mozley PD. Malignant hyperthermia following intravenous iodinated contrast media. Report of a fatal case. Diagn Gynecol Obstet 1981;3:81-6. https://pubmed.ncbi.nlm.nih.gov/7011755/

55.Dunford J. Fatal ascending tonic-clonic seizure syndrome. Ann Emerg Med 1998;32:624-6. https://doi.org/10.1016/s01960644(98)70045-9

56. Rosenberg $\mathrm{H}$, Antognini JF, Muldoon S. Testing for malignant hyperthermia. Anesthesiol 2002;96:232-7.

https://doi.org/10.1097/00000542-200201000-00036

57.Robinson RL, Monnier N, Wolz W, Jung M, Reis A, Nuernberg G, et al. A Genome Wide Search for Susceptibility Loci in Three European Malignant Hyperthermia Pedigrees. Hum Mol Gen 1997:6:953961. https://doi.org/10.1093/hmg/6.6.953

58. Robinson RL, Curran JL, Hall WJ, Halsall PJ, Hopkins PM, Markham $A F$, et al. Genetic heterogeneity and HOMOG analysis in British malignant hyperthermia families. J Med Genet 1998;35:196-201. https://doi.org/10.1136/jmg.35.3.196

59.Girard T, Jöhr M, Schaefer C, Urwyler A. Perinatal diagnosis of malignant hyperthermia susceptibility. Anesthesiology 2006;104:1353-4. https://doi.org/10.1097/00000542-20060600000052

60.Suggested guidelines for management of the pregnant patient not believed to be at risk for $\mathrm{MH}$, but whose partner is susceptible to malignant hyperthermia (endereço na Internet). acessado em 2012. https://www.mhaus.org/healthcare-professionals/mhaus-

recommendations/parturient-with-mhs-partner/

61.Krivosic-Horber R, Adnet P, Krivosic I, Reyford H. Diagnostic de la sensibilité à l'hyperthermie maligne chez l'enfant [Diagnosis of susceptibility to malignant hyperthermia in children]. Arch Fr Pediatr 1990;47:421-4. https://pubmed.ncbi.nlm.nih.gov/2403268/

62.Stowell K, Pollock N, Langton E. Perinatal diagnosis of malignant hyperthermia susceptibility. Anaesth Inten Care 2007;35:454-5. https://pubmed.ncbi.nlm.nih.gov/17591153/

63. Robinson RL, Hopkins PM. A breakthrough in the genetic diagnosis of malignant hyperthermia. $\mathrm{Br} J$ Anaesth 2001;86:166-8. https://doi.org/10.1093/bja/86.2.166. doi: 10.1093/bja/86.2.166 
64.O'Brien PJ, Klip A, Britt BA, Kalow BI. Malignant hyperthermia susceptibility: biochemical basis for pathogenesis and diagnosis. Can J Vet Res 1990;54:83-92. https://pubmed.ncbi.nlm.nih.gov/2155050/ 65 . Wynands JE. Amrinone: is it the inotrope of choice? J Cardiothorac Anesth 1989;3(6 Suppl 2):45-57. https://doi.org/10.1016/08886296(89)90059-8

66.Fiege M, Wappler F, Weisshorn R, Gerbershagen MU, Kolodzie K, Esch JS. Phosphodiesterase-III-inhibition with amrinone leads to contracture development in skeletal muscle preparations of malignant hyperthermia susceptible swine. Eur ] Anaesthesiology 2005;22:2838. https://doi.org/10.1017/s0265021505000475

67.Fiege M, Wappler F, Weisshorn R, Gerbershagen MU, Kolodzie K, Schulte Am Esch J. In vitro and in vivo effects of the phosphodiesterase-III inhibitor enoximone on malignant hyperthermia-susceptible swine. Anesthesiology 2003;98:944-9. https://doi.org/10.1097/00000542-200304000-00022

68. Riess FC, Fiege M, Moshar S, Bergmann H, Bleese N, Kormann J, et al. Rhabdomyolysis following Cardiopulmonary Bypass and Treatment with Enoximone in a Patient Susceptible to Malignant Hyperthermia. Anesthesiology 2001;94;355-7. https://doi.org/10.1097/00000542200102000-00029

69.Fiege M, Wappler F, Scholz J, von Richthofen V, Brinken B, Schulte am Esch J. Diagnostik der Disposition zur malignen Hyperthermie durch einen in vitro Kontrakturtest mit dem Phosphodiesterase-IIIHemmstoff Enoximon [Diagnosis of susceptibility to malignant hyperthermia with an in vitro contracture test with the phosphodiesterase iii inhibitor enoximone]. Anasthesiol Intensivmed Notfallmed Schmerzther 1998;33:557-63. https://doi.org/10.1055/s2007-994811

70.Fiege M, Wappler F, Scholz J, Weisshorn R, von Richthofen V, Schulte am Esch J. Effects of the phosphodiesterase-III inhibitor enoximone on skeletal muscle specimens from malignant hyperthermia susceptible patients. J Clin Anesth 2000;12:123-8. https://doi.org/10.1016/s0952-8180(00)00124-0

71.Sica DA. Pharmacotherapy review: calcium channel blockers. J Clin Hypertens 2006;8:53-6. https://doi.org/10.1111/j.1524$6175.2005 .04140 . x$

72. Foster PS, Denborough MA. Effect of diltiazem and dantrolene on the contractility of isolated malignant hyperpyrexia-susceptible porcine skeletal muscle. $\mathrm{Br}$ J Anaesth 1989;62:566-72. https://doi.org/10.1093/bja/62.5.566

73.Ilias WK, Williams CH, Fulfer RT, Dozier SE. Diltiazem inhibits halothane-induced contractions in malignant hyperthermia-susceptible muscles in vitro. $\mathrm{Br} J$ Anaesth 1985;57:994-6. https://doi.org/10.1093/bja/57.10.994

74.Foster PS, Denborough MA. The effect of calcium channel antagonists and BAY K 8644 on calcium fluxes of malignant hyperpyrexia-susceptible muscle. Int J Biochem 1993;25:495-504. https://doi.org/10.1016/0020-711x(93)90656-y 
75.Saltzman LS, Kates RA, Corke BC, Norfleet EA, Heath KR. Hyperkalemia and Cardiovascular Collapse after Verapamil and Dantrolene Administration in Swine. Anesth Analg 1984;63:473-8. https://pubmed.ncbi.nlm.nih.gov/6711841/

76.Lynch C, Durbin CG Jr, Fisher NA, Veselis RA, Althaus JS. Effects of dantrolene and verapamil on atrioventricular conduction and cardiovascular performance in dogs. Anesth Analg 1986;65:252-8. https://pubmed.ncbi.nlm.nih.gov/3954091/

77.Keilani MR, Al-Shanableh JS. Verapamil and malignant hyperthermia - case reports. Middle East J Anaesthesiol 1985;8:37-45. https://pubmed.ncbi.nlm.nih.gov/4010529/

78.Rubin AS, Zablocki AD. Hyperkalemia, verapamil, and dantrolene. Anesthesiology 1987;66:246-9. https://doi.org/10.1097/00000542198702000-00028

79.Migita T, Mukaida K, Yasuda T, Hamada H, Kawamoto M. Calcium channel blockers are inadequate for malignant hyperthermia crisis. J Anesth 2012;26:579-84. https://doi.org/10.1007/s00540-012-1347$\underline{0}$

80.Adnet PJ, Krivosic-Horber M, Haudecoeur G, Reyford HG, Adamantidis MM, Dupuis BA. Diltiazem and nifedipine reduce the in vitro contracture response to halothane in malignant hyperthermiasusceptible muscle. Can J Anaesth 1990;37:556-9. https://doi.org/10.1007/BF03006325

81.Gallant EM, Foldes FF, Rempel WE, Gronert GA. Verapamil is not a therapeutic adjunct to dantrolene in porcine malignant hyperthermia. Anesth Analg https://pubmed.ncbi.nlm.nih.gov/4003778/

82.Czuriga I, Edes I. Béta-adrenerg-receptor-blokkolók a klinikai gyakorlatban [Beta-adrenergic receptor blockers in clinical practice]. Orv Hetil 2004;145:1951-60.

https://pubmed.ncbi.nlm.nih.gov/15535106/

83.Ording $\mathrm{H}$. Influence of propranolol on the in vitro response to caffeine and halothane in malignant hyperthermia-susceptible muscle. Acta Anaesthesiol Scand 1989:33:405-8.

https://doi.org/10.1111/j.1399-6576.1989.tb02933.x

84.Møller-Petersen J, Andersen PT, Hjørne N, Ditzel J. Nontraumatic rhabdomyolysis during diabetic ketoacidosis.

Diabetologia 1986;29:229-34. https://doi.org/10.1007/BF00454881 85. Kilbane BJ, Mehta S, Backeljauw PF, Shanley TP, Crimmins NA. Approach to management of malignant hyperthermia-like syndrome in pediatric diabetes mellitus. Pediatr Crit Care Med 2006;7:169-73. https://doi.org/10.1097/01.PCC.0000192340.09136.82 
86.Genetics Home Reference. Genetic Conditions. The deficiency in acyl-CoA dehydrogenase short-chain. Short-chain acyl-CoA dehydrogenase deficiency (endereço na internet). (acessado em: 2009). Disponível em:

https://rarediseases.info.nih.gov/diseases/4822/short-chain-acylcoa-

dehydrogenasedeficiency\# : : text=Short\%2Dchain \%20acyl\%2DCoA $\% 20$ dehydrogenase $\% 20$ (SCAD) $\% 20$ deficiency $\% 20$ is, acid\%20oxidatio n\%20disorders\%20(FOD).

87. Wappler F, Scholz J, Fiege M, Kolodzie K, Kudlik C, Weibhorn R, et al. 4-Chloro-m-cresol is a Trigger of Malignant Hyperthermia in Susceptible Swine. Anesthesiology 1999;90:1733-40. https://doi.org/10.1097/00000542-199906000-00031

88. Freymond $D$, Dériaz $O$, Frascarolo $F$, Reiz $S$, Jéquier $E$, Urwyler $A$. In Vivo Whole-Body Resting Energy Expenditure and Insulin Action in Human Malignant Hyperthermia. Anesthesiology 2000;93:39-47. https://doi.org/10.1097/00000542-200007000-00011

89.Wappler F, Roewer N, Köchling A, Braune H, Reissinger T, Schulte am Esch J. Fulminant malignant hyperthermia associated with ketoacidotic diabetic coma. Intensive Care Med 1996;22:809-12. https://doi.org/10.1007/BF01709525

90. Hollander AS, Olney RC, Blackett PR, Marshall BA. Fatal malignant hyperthermia-like syndrome with rhabdomyolysis complicating the presentation of diabetes mellitus in adolescent males. Pediatrics 2003;111:1447-52. https://doi.org/10.1542/peds.111.6.1447

91.Baluch AR, Oommen SP. Malignant hyperthermia associated with diabetic hyperosmolar hyperglycemic nonketotic state in a young man. J Clin Anesth 2007;19:470-2.

https://doi.org/10.1016/j.jclinane.2006.12.008

92.Tammineni ER, Kraeva N, Figueroa L, Manno C, Ibarra CA, Klip A, et al. Intracellular calcium leak lowers glucose storage in human muscle, promoting hyperglycemia and diabetes. eLife 2020;9:e53999. https://doi.org/10.7554/eLife.53999

93.0'Leary G, Nargiso J, Weiss R. 3, 4 methylenedioxymethamphethamine (MDMA): a Review. Curr Psychiatry Rep 2001;3:477-83. https://doi.org/10.1007/s11920-0010041-y

94. Hall AP, Henry JA. Acute toxic effects of "Ecstasy" (MDMA) and related compounds: overview of pathophysiology and clinical management. $\mathrm{Br}$ J Anaesth 2006;96:678-85.

https://doi.org/10.1093/bja/ael078

95.Fiege M, Wappler F, Weisshorn R, Gerbershagen MU, Menge M, Schulte Am Esch J. Induction of malignant hyperthermia in susceptible swine by 3,4-methylenedioxymethamphetamine ("ecstasy"). Anesthesiology 2003;99:1132-6. https://doi.org/10.1097/00000542200311000-00020

96.Denborough MA, Hopkinson KC. Dantrolene and "ecstasy". MJA 1997; 166:165-6. https://doi.org/10.5694/j.1326-

5377.1997.tb140056.x 
97.Klingler W, Heffron JJA, Jurkat-Rott K, O'Sullivan G, Alt A, Schlesinger $\mathrm{F}$, et al. 3,4-Methylenedioxymethamphetamine (Ecstasy) Activates Skeletal Muscle Nicotinic Acetylcholine Receptors. J Pharmacol Exp Ther 2005;314:1267-73.

https://doi.org/10.1124/jpet.105.086629

98.Fiege M, Wappler F, Weisshorn R, Gerbershagen MU, Esch JS. Effects of Theophylline on Anesthetized Swine Susceptible for Malignant Hyperthermia In-Vivo. Anesthesiology 2001;95:A1015. http://www.asaabstracts.com/strands/asaabstracts/abstract.htm?yea $r=2001 \&$ index $=12 \&$ absnum $=1147$

99.Gerbershagen MU, Fiege M, Weisshorn R, Kolodzie K, Wappler F. Theophyllin induziert Kontrakturen an Skelettmuskelpraparaten des Scweines mit Disposition zu Maligner Hyperthermie. Anasthesiol Intensivmed Notfallmed Schmerzther 2004;39:147-52. https://doi.org/10.1055/s-2004-814328

100. Mucklow JC, Kuhn S. The rise and fall of serum theophyline concentration: a comparison of sustained-release formulations in volunteers with rapid theophylline clearance. $\mathrm{Br} \mathrm{J}$ Clin Pharmacol $1985 ; 20: 589-96$.

https://doi.org/10.1111/j.1365-

2125.1985.tb05116.x

101.Fiege M, Wappler F, Weisshorn R, Kolodzie K, Esch JS. In-vitro Contracture Test with Theophylline - An Alternative in Diagnosis of Malignant Hyperthermia? Anesthesiology 2002;96:A1201.

102. Bosetti C, Negri E, Fattore E, La Vecchia C. Occupational exposure to polychlorinated biphenyls and cancer risk. Eur J Cancer Prev 2003; 12:251-5. 00002

103.Ta TA, Pessah IN. Ryanodine receptor type 1 (RyR1) possessing malignant hyperthermia mutation $\mathrm{R} 615 \mathrm{C}$ exhibits heightened sensitivity to dysregulation by non-coplanar 2,2,3,5,6 pentachlorobiphenyl (PCB 95). NeuroToxicology 2007;28:770-9. https://doi.org/10.1016/j.neuro.2006.08.007

104.Pessah IN, Allen PD. Malignant hyperthermia. Best Pract Res Clin Anaesthesiol 2001;15:277-88.

https://doi.org/10.1053/bean.2001.0156

105.Pelonero AL, Levenson JL, Pandurangi AK. Neuroleptic malignant syndrome: a review. Psychiatr Serv 1998;49:1163-72. https://doi.org/10.1176/ps.49.9.1163

106. Adnet $\mathrm{P}$, Lestavel $\mathrm{P}$, Krivosic-Horber R. Neuroleptic malignant syndrome. $\mathrm{Br}$ J Anaesth 2000;85:129-35.

https://doi.org/10.1093/bja/85.1.129

107. Hermesh $\mathrm{H}$, Aizenberg $\mathrm{D}$, Lapidot M, Munitz H. Risk of malignant hyperthermia among patients with neuroleptic malignant syndrome and their families. Am J Psychiatry 1988;145:1431-4. https://doi.org/10.1176/ajp.145.11.1431

108.Calore EE, Cavaliere MJ, Perez NM, Russo DH, Wakamatsu A, Razzouk D. Hyperthermic reaction to haloperidol with rigidity, associated to central core disease. Acta Neurol 1994;16:157-61. https://pubmed.ncbi.nlm.nih.gov/7856468/ 
109.Portel L, Hilbert G, Gruson D, Favier JC, Gbikpi-Benissan G, Cardinaud JP. Malignant hyperthermia and neuroleptic malignant syndrome in a patient during treatment for acute asthma. Acta Anaesthesiol Scand 1999;43:107-10. https://doi.org/10.1034/j.13996576.1999.430123.x

110.Russell T, Riazi S, Kraeva N, Steel AC, Hawryluck LA. Ecstacyinduced delayed rhabdomyolysis and neuroleptic malignant syndrome in a patient with a novel variant in the ryanodine receptor type 1 gene. Anaesthesia 2012;67:1021-4. https://doi.org/10.1111/j.13652044.2012.07226.x

111.American Psychiatric Association. Diagnostic and Statistical Manual of Mental Disorders-Text Revision. 4th ed. Washington (DC): APA; 2000.

112. Caroff SN, Rosenberg H, Fletcher JE, Heiman-Patterson TD, Mann SC. Malignant hyperthermia susceptibility in neuroleptic malignant syndrome. Anesthesiology 1987;67:20-5.

https://doi.org/10.1097/00000542-198707000-00004

113.Tollefson G. A case of neuroleptic malignant syndrome: in vitro muscle comparison with malignant hyperthermia. J Clin Psychopharmacol 1982;2:266-70.

https://pubmed.ncbi.nlm.nih.gov/6126494/

114.Scarlett JD, Zimmerman R, Berkovic SF. Neuroleptic malignant syndrome. Aust NZ J Med 1983;13:70-3. https://doi.org/10.1111/j.1445-5994.1983.tb04554.x

115.Denborough MA, Collins SP, Holkinson KC. Rhabdomyolysis and malignant hyperpyrexia. $\mathrm{Br}$ Med J 1984;28:1878. https://doi.org/10.1136/bmj.288.6434.1878

116. Merry SN, Merry AF. Neuroleptic malignant syndrome and malignant hyperthermia. [Letter] N Z Med J 1988;101:431.

117.Krivosic-Horber R, Adnet P, Guevart E, Theunynck D, Lestavel P. Neuroleptic malignant syndrome and malignant hyperthermia. In vitro comparison with halothane and caffeine contracture tests. $\mathrm{Br}$ J Anaesth 1987; 59:1554-6. https://doi.org/10.1093/bja/59.12.1554

118. Adnet PJ, Krivosic-Horber RM, Adamantidis MM, Haudecoeur G, Adnet-Bonte CA, Saulnier $F$, et al. The association between the neuroleptic malignant syndrome and malignant hyperthermia. Acta Anaesthesiol Scand 1989;33:676-80. https://doi.org/10.1111/j.13996576.1989.tb02990.x

119.Silva HCA, Bahia VS, Oliveira RAA, Marchiori PE, Scaff M, Tsanaclis AMC. Susceptibilidade à hipertermia maligna em três pacientes com síndrome maligna por neurolépticos. Arq Neuropsiquiatr 2000:58:7139. https://doi.org/10.1590/S0004-282X2000000400018

120.Araki M, Takagi A, Higuchi I, Sugita H. Neuroleptic malignant syndrome: caffeine contracture of single muscle fibers and muscle pathology. Neurology 1988;38:297-301.

https://doi.org/10.1212/wnl.38.2.297

121. Fletcher JE, Rosenberg $\mathrm{H}$, Lizzo FH. Effects of droperidol, haloperidol and ketamine on halothane, succinylcholine and caffeine contractures: implications for malignant hyperthermia. Acta 
Anaesthesiol Scand 1989;33:187-92. https://doi.org/10.1111/j.13996576.1989.tb02887.x

122. Sato T, Nishio $H$, Iwata M, Kentotsuboi, Tamura A, Miyazaki T, et al. Postmortem molecular screening for mutations in ryanodine receptor type 1 (RYR1) gene in psychiatric patients suspected of having died of neuroleptic malignant syndrome. Forensic Sci Int 2010;194:779. https://doi.org/10.1016/j.forsciint.2009.10.014

123. Chen IC, Lin CS, Chou HM, Peng TH, Liu CH, Wang CF, et al. Unexpected recurrent seizures following repeated spinal injections of tetracaine - a case report. Acta Anaesthesiol Sin 2000;38:1036. https://pubmed.ncbi.nlm.nih.gov/11000675/

124. Murray C, Sasaki SS, Berg D. Local anesthesia and malignant hyperthermia: review of the literature and recommendations for the dermatologic surgeon. Dermatol Surg 1999;25:626-30. https://doi.org/10.1046/j.1524-4725.1999.98214.x

125.Terry D. Halothane, Dental Anaesthesia and Children. Saad Digest 2000;17:26. https://pubmed.ncbi.nlm.nih.gov/11404913/

126. Haas DA, Young ER, Harper DG. Malignant hyperthermia and the general dentist: current recommendations. J Can Dent Assoc 1992;58:28-33. Erratum in: J Can Dent Assoc 1992;58:256. https://pubmed.ncbi.nlm.nih.gov/1531939/

127. Noguchi I, Ohno H, Takano K, Shimada R, Sasao M, Shimonaka H. Fatal hyperthermia due to dental treatment. Oral Surg Oral Med Oral Pathol Oral Radiol Endod 2006;101:e61-4.

https://doi.org/10.1016/j.tripleo.2005.07.001

128.D'Ambrosio J, Adragna MG. Guidelines for the use of local anesthetics in the dental treatment of patients who are susceptible to malignant hyperthermia. Spec Care Dentist 1988;8:61-3. https://doi.org/10.1111/j.1754-4505.1988.tb00693.x

129.Nagasawa M. Effects of 4-hydroxybenzoic acid methyl ester on the $\mathrm{Ca}(2+)$-related functions of skinned skeletal muscle fibers from the guinea pig. Masui 2000;49:369-75.

https://pubmed.ncbi.nlm.nih.gov/10793521/

130.Motegi Y, Shirai M, Arai M, Kato S, Kawana Y, Goto F. Malignant hyperthermia during epidural anesthesia. J Clin Anesth 1996;8:15760. https://doi.org/10.1016/0952-8180(95)00204-9

131. Sheu CC, Tsai JR, Hung JY. Possible malignant hyperthermia during spinal anaesthesia with tetracaine. Anaesthesia 2007;62:2001. https://doi.org/10.1111/j.1365-2044.2007.04969.x

132.Kemp DR, Choong LS. Malignant hyperthermia and the conscious patient. Aust N Z J Surg 1988;58:423-7.

https://doi.org/10.1111/j.1445-2197.1988.tb01092.x

133. Minasian A, Yagiela JA. The use of amide local anesthetics in patients susceptible to malignant hyperthermia. Oral Surg Oral Med Oral Pathol 1988;66:405-15. https://doi.org/10.1016/00304220(88)90256-3

134.Iaizzo PA, Johnson BA, Nagao K, Gallagher WJ. 4-chloro-m-cresol triggers malignant hyperthermia in susceptible swine at doses greatly exceeding those found in drug preparations. Anesthesiology 
1999;90:1723-32. $\quad$ https://doi.org/10.1097/00000542-199906000$\underline{00030}$

135.Lichtman AD, Oribabor C. Malignant hyperthermia following systemic rewarming after hypothermic cardiopulmonary bypass. Anesth Analg 2006;102:372-5.

https://doi.org/10.1213/01.ane.0000189596.70694.36

136.Baur CP, Bellon L, Felleiter P, Fiege M, Fricker R, Glahn K, et al. A multicenter study of 4-chloro-m-cresol for diagnosing malignant hyperthermia susceptibility. Anesth Analg 2000;90:200-5. https://doi.org/10.1097/00000539-200001000-00040

137. Wappler F, Anetseder M, Baur CP, Censier K, Doetsch S, Felleiter $\mathrm{P}$, et al. Multicentre evaluation of in vitro contracture testing with bolus administration of 4-chloro-m-cresol for diagnosis of malignant hyperthermia susceptibility. Eur J Anaesthesiol 2003;20:528-36. https://doi.org/10.1017/s026502150300084x

138. Anetseder $M$, Ritter L, Horbaschek H, Hartung E, Roewer N. The impact of 4-chloro-m-cresol in heparin formulas on malignant hyperthermia: in vitro and in vivo. Acta Anaesthesiol Scand 2000;44:338-42.

$\underline{6576.2000 .440321 . x}$ https://doi.org/10.1034/j.1399- 